
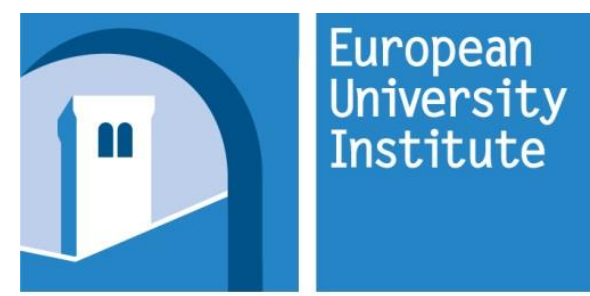

ROBERT

SCHUMAN

CENTRE FOR

ADVANCED

STUDIES

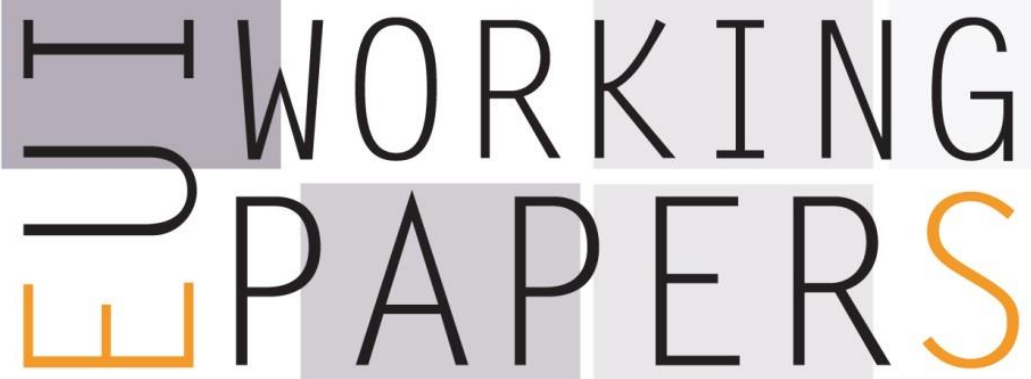

RSCAS 2014/99

Robert Schuman Centre for Advanced Studies Climate Policy Research Unit

EU Emissions Trading by Energy Firms

Thijs Jong and Alexander C.M. Zeitlberger 

European University Institute

Robert Schuman Centre for Advanced Studies

Climate Policy Research Unit

\section{EU Emissions Trading by Energy Firms}

Thijs Jong and Alexander C.M. Zeitlberger

EUI Working Paper RSCAS 2014/99 
This text may be downloaded only for personal research purposes. Additional reproduction for other purposes, whether in hard copies or electronically, requires the consent of the author(s), editor(s). If cited or quoted, reference should be made to the full name of the author(s), editor(s), the title, the working paper, or other series, the year and the publisher.

ISSN 1028-3625

(C) Thijs Jong and Alexander C.M. Zeitlberger, 2014

Printed in Italy, October 2014

European University Institute

Badia Fiesolana

I - 50014 San Domenico di Fiesole (FI)

Italy

www.eui.eu/RSCAS/Publications/

www.eui.eu

cadmus.eui.eu 


\section{Robert Schuman Centre for Advanced Studies}

The Robert Schuman Centre for Advanced Studies (RSCAS), created in 1992 and directed by Brigid Laffan since September 2013, aims to develop inter-disciplinary and comparative research and to promote work on the major issues facing the process of integration and European society.

The Centre is home to a large post-doctoral programme and hosts major research programmes and projects, and a range of working groups and ad hoc initiatives. The research agenda is organised around a set of core themes and is continuously evolving, reflecting the changing agenda of European integration and the expanding membership of the European Union.

Details of the research of the Centre can be found on:

http://www.eui.eu/RSCAS/Research/

Research publications take the form of Working Papers, Policy Papers, Distinguished Lectures and books. Most of these are also available on the RSCAS website:

http://www.eui.eu/RSCAS/Publications/

The EUI and the RSCAS are not responsible for the opinion expressed by the author(s).

\section{Climate Policy Research Unit}

The Climate Policy Research Unit (CPRU) is a research group within the Robert Schuman Centre for Advanced Studies under the Loyola de Palacio Chair. The goal of the CPRU is to provide a reliable source for information and analysis of EU climate policy and a forum for discussion of research carried out in this area among government officials, academics and industry.

The CPRU was established in 2010 at the initiative of Josep Borrell, President of the EUI and former President of the European Parliament, as a means of providing more focus to European climate policy developments. The director of the CPRU is Xavier Labandeira, part-time professor at the RSCAS, and professor at the Department of Applied Economics at the University of Vigo, Spain. The CPRU works in collaboration with the energy and regulatory policy research groups of the Florence School of Regulation and Loyola de Palacio Chair and with the Global Governance Programme at the EUI. Starting in 2012, the CPRU has been funded primarily by the European Commission (DG Clima).

The opinions expressed in this paper are those of the author(s) and do not represent the views of the European University Institute or any of its subsidiary components or those of the European Commission.

For more information:

http://fsr.eui.eu/CPRU/Index.aspx 



\begin{abstract}
This paper aims to identify what determines the allowance transactions of energy firms on the European carbon market (EU ETS). We develop measures of their 'autarky' regarding the carbon market, their allowance hedging, and the allowance holdings which ensure optimal EU ETS compliance. Although under-allocated over Phase I, energy firms held more allowances than needed. By selling allowances, only the non-autarkic firms followed their optimal compliance holdings and, hence, actually behaved autarkical. Autarkic firms, conversely, purchased more allowances than they needed. Moreover, and unlike non-autarkic firms, their allowance trades were responsive to energy demand and indicative of carbon hedging. Finally, all energy firms utilized the carbon market's abatement potential, which affirms that the EU ETS leads to relative cost savings. As especially autarkic energy firms utilized this potential, and may have reaped additional savings from their active hedging, they behaved least autarkical regarding the carbon market.
\end{abstract}

\title{
Keywords
}

Emissions trading ; energy market ; EU Transaction Log ; firm-level data ; allowance purchases and sales ; carbon hedging; panel data econometrics

JEL codes: D22 ; H23 ; L94 ; Q41 ; Q52 



\section{Introduction ${ }^{1}$}

The European Union's Emission Trading Scheme (EU ETS) was launched in 2005 in order to cost-effectively reduce greenhouse gases from several industry sectors. The mechanism behind the EU ETS is a cap-and-trade system, where the 'cap' is the aggregate sum of the EU Member States' emissions reduction targets, and the subsequent 'trade' in allowances underlying the cap is left to the market.

Recent research shows that only few firms traded carbon allowances during EU ETS Phase I (2005-2007) (see e.g. Martino and Trotignon (2013), Zaklan (2013), Jaraitè and Kažukauskas (2012), and Jong et al. (2014)). The energy sector was 'forced' to trade allowances as it was the only 'under-allocated' sector (i.e. it needed more allowances to cover its emissions than it received in allowance allocations). ${ }^{2}$ Energy firms are therefore expected to only purchase allowances for covering these shortfalls. However, transactions from the EU Transaction Log (EUTL) indicate that most energy firms both bought and sold allowances. Some adjustments to these allowance holdings must have been carried out due to changes in the carbon contents of production. For example, increases in gas prices may increase demand for allowances because higher gas prices make coal, being more carbon-intensive than gas, relatively cheap in the production of energy. Other allowance holdings adjustments may relate to the cost minimization of compliance, including the hedging of carbon allowances. So far, however, there is no empirical literature analysing the actual allowance trading of energy firms, the key drivers, and their relative importance. The aim of this paper is therefore to fill this literature gap by analysing both energy market and energy firm-specific characteristics, the resulting range of factors

\footnotetext{
${ }^{1}$ Thijs Jong's research has been financed by the Energy Delta Gas Research (EDGaR) program. EDGaR is co-financed by the Northern Netherlands Provinces, the European Fund for Regional Development, the Netherlands Ministry of Economic Affairs, Agriculture and Innovation and the Province of Groningen. We are grateful for the useful comments we received from Oscar Couwenberg, Edwin O. Fischer, Henryk Gurgul, Michael Murg, Matthias Pachler, Herwig Pilaj, Stefan P. Schleicher, and Edwin Woerdman. Any remaining errors are our own.

${ }^{2}$ EU Member States made energy firms short on allowances, as they are considered able to costeffectively abate pollution through fuel switching, and as they do not compete on an international market (see e.g. Ellerman et al. (2007), Part I).
} 
of which enables us to obtain an integrated account of their allowance trade behaviour towards the EU ETS.

The central question of this paper is: which EU ETS and energy industry factors determined the allowance amounts traded by energy firms over EU ETS Phase I?

The paper is organized as follows. Section 2 reviews the literature on allowance trading incentives for energy firms, and formulates hypotheses. Section 3 discusses the methodological framework and variables definitions. The descriptive statistics are presented in Section 4, while the empirical results are provided in Section 5. Section 6 concludes the paper.

\section{Why firms trade}

In general, the incentive to trade allowances depends on the gains firms expect to attain vis-à-vis the opportunity costs of not trading (e.g. of abating pollution or keeping unused allowances in stock). The benefits and costs to trade may be affected by several institutional constraints, ranging from tradeability restrictions, restrictions on banking and borrowing, different allocation methods, regulatory uncertainty regarding the future allowance cap, transaction costs regarding monitoring, as well as information, search and bargaining costs. Specifically, Hanemann (2010) outlines two main features with regard to allowance trade incentives. The first is what is called 'autarky' (Kreutzer (2006)): firms first cut emissions, borrow from future allocations, or exchange allowances between subsidiaries before they opt for the market. The second feature is that firms are typically allowed to store or 'bank' their allowances within and/or between compliance periods, which enables them to smooth firm-specific or market shocks over time. ${ }^{3}$

This 'autarkic' behaviour is also observed for the EU ETS energy industry. Jaraite and Di Maria (2012) show that the introduction of the EU ETS led the energy sector to abate emissions. Furthermore, Alberola and Gloaguen (2013) assert that not the EU carbon

\footnotetext{
${ }^{3}$ Only EU ETS Phase I (2005-2007) allowances could not be banked towards later Phases.
} 
targets, but mainly those on renewables and energy efficiency led to emission reductions, although fewer emission reductions would have taken place without the carbon price in place. Also the borrowing and intra-firm exchange of allowances is indicative of the energy sector's autarkic behaviour. The sector is shown to have borrowed most from its subsequent allocations (Jong et al. (2014)), and firms in the combustion (i.e. energy) sector were most likely to trade between their subsidiaries, and the more so when firms were larger (Jaraitė and Kažukauskas (2012); Zaklan (2013)).

We postulate that, within the energy industry, cost-minimizing firms behave autarkical if they can flexibly adjust their carbon-intensity of production. Advantageous for energy firms in managing their carbon-intensity is that both parts of this ratio can be adjusted. This is more feasible if firms control more and diverse production sources, as it allows them to spread the same production over different numbers of installations and/or over different fuel-sourced installations (i.e. fuel switching). Hence, not only will pollution abatement be facilitated, but also the pooling, borrowing, and/or banking of allowances within firm boundaries, so that the carbon market will only be used for any remaining allowance demand or supply.

Furthermore, as energy production is volatile and typically planned months or even years in advance, derivative markets play a key role in managing these risks. As carbon pollution has become part of a firm's production costs, also carbon risks would need to be hedged for. ${ }^{56}$ Indeed, and based on the reasoning in Smith Jr. (2008), firms are more likely to hedge on the market when they have fewer possibilities within firm boundaries to smooth their carbon-related costs; in other words, when they cannot behave autarkical.

\footnotetext{
${ }^{4}$ EU ETS Directive 2003/87/EC allows (de facto) borrowing of allowances, as the next calendar year's allocation will be received (in February) before the current year's allowances need to be surrendered (in April).

${ }^{5}$ The possibility to bank allowances is one of the main conditions for carbon derivatives (see e.g. Maeda (2004)). Indeed, allowance banking has been an efficient strategy to reduce compliance costs (e.g. Ellerman and Montero (2007))

${ }^{6}$ Yet, due to the (resulting) volatile and discontinuous behaviour of the carbon price, hedging structures can unexpectedly lose their optimality (Daskalakis et al. (2009)). Carbon hedging structures thus depend on the selected time-frames and market prices.
} 
However, empirical literature on EU firms' autarkic behaviour as well as their carbon allowance banking and hedging behaviour is almost non-existent. ${ }^{7}$ The main reason is that, besides allocations and emissions, allowance transactions data are needed to obtain estimates on the allowance banks, hedges, and (therefore) the self-sufficiency or autarkic stance vis-à-vis the carbon market. This transaction data is difficult to obtain from the EUTL and it is not at firm-level, while it is provided with a time delay. ${ }^{8}$ Much of the carbon market literature is therefore predominantly based on allocations and emissions only, thereby disregarding trade-behavioural aspects on the carbon profile of firms. This shortcoming is more pressing since the energy sector had the largest share of inter-firm trade in the EU ETS (Jong et al. (2014)). The literature is therefore scarce what the optimal allowance holdings are, and whether these optimal holdings are actually followed by firms subject to emissions trading schemes.

This paper fills a gap by analysing both energy market and energy firm-specific characteristics, the resulting range of factors of which enables us to obtain an integrated account of their behaviour towards the EU ETS. We hypothesize that cost-minimizing firms first try to behave 'autarkical' by smoothing production and emissions and, hence, carbon costs within firm boundaries, which means that firms will trade and hedge less on the carbon market. The subsequent hypothesis is that over time, and towards the end of Phase I, firms follow their 'compliance trajectory': by adjusting their allowance holdings to minimize any differences between their allocations and emissions. Finally, we include factors capturing the financial aspect of allowance trades. As a result, this paper contributes to the understanding of carbon and energy market linkages at both micro

\footnotetext{
${ }^{7}$ Most literature analysing changes in the allowance holdings of firms focuses on US emissions trading schemes. Examples of findings are that $\mathrm{SO}_{2}$ allowance holdings are responsive to future changes in the cap (Ellerman and Montero (2007)). Firms with higher $\mathrm{SO}_{2}$ pollution rates maintain relatively more allowances for precautionary purposes (Rousse and Sevi (2007)). Allowance holdings respond as expected to the convenience yield, and to price differences between low and high-sulphur coal (Considine and Larson (2006)). However, plant owners did not appear to take full advantage of the available cost savings the $\mathrm{SO}_{2}$ allowance market offered (Swinton (2004)).

${ }^{8}$ This delay used to be 5 years, but a recent Commission Regulation (no. 389/2013) decreased it to 3 years. As Phase I allowances become void in Phase II, an analysis on Phase I is still useful as firms are incentivized to round off their allowance holdings.
} 
and macro-levels. Both for policy-makers and the industry these insights will be crucial for a better understanding of the functioning of the EU ETS.

\section{Methodology}

To accommodate for both time and firm effects, we apply a panel model framework as follows:

$$
Y_{i, t}=\beta_{i} X_{i, t}+\epsilon_{i, t}
$$

where subscript $i$ stands for the individual firm, and $t$ for the trading day; vector $Y_{i, t}$ is the dependent variable capturing the daily amounts traded (Section 3.3); $X_{i, t}$ contains an intercept, time dummies, and three groups of determinants: 1) those affecting production and emissions (Section 3.4), 2) trade and hedging (Section 3.5), and 3) the compliance trajectory (Section 3.6). $\epsilon_{i, t}$ contains the idiosyncratic shocks $\nu_{i, t}$, and may contain unobserved fixed effects $\mu_{i}$.

\subsection{Data clustering}

Next to tackling the fixed effects via the panel model framework, we account for firm heterogeneity via subgroups based on indicators of autarkic behaviour and the firms' trade frequency. For both we apply an additional indicator, in order to check whether these subgroups are properly defined (Appendix A.4 provides details on the density of firms over these subgroup combinations). All four indicators are turned into dummies, where indicator-values above the sample median equal 1 , and 0 otherwise. The two trade frequency indicators are applied as subsets and, within these subsets, the two autarky indicators are applied as interaction terms. Depending on the regression fits, we will subsequently select one of the two autarky indicators.

Through the trade frequency subset, we aim to expose differences in allowance trade incentives. The first indicator we consider is the trade dispersion $\left(D I S P_{i}\right)$, which is the firm's average Phase I allowance trade divided by its Phase I total amount exchanged. 
As frequent traders have more dispersed trades, their $D I S P_{i}$-values approach 0 . For infrequent traders, $D I S P_{i}$ approaches one. Moreover, as electricity firms are among the most active on the carbon market (e.g. Jong et al. (2014)), for the additional indicator we constructed a dummy $\left(E L E C_{i}\right)$ equalling 1 if firms control at least one electricity installation, and 0 otherwise. The non-electricity firms are active in the remaining part of the electricity value chain, such as fuel extraction, and the trade and transport of energy. ${ }^{9}$ For the remainder of the text, references to "energy" firms will encompass both electricity and non-electricity firms.

We further conjecture that firms behave autarkical if they can flexibly adjust their carbon-intensity (cf. Section 2). We constructed a composite indicator $\left(E N D O W_{i}\right)$ from a set of constant and/or annual variables affecting the firms' carbon-intensity (more details can be found in Appendix A.3). Expected is that autarkic behaviour is more likely, and $E N D O W_{i}$ will be larger in value, if firms are more endowed: by owning more domestic and foreign installations, by having more electricity and non-electricity subsidiaries within their conglomerates, more heterogeneous fuel inputs, and larger market shares and carbon intensities. Finally, as large firms are likely to behave autarkical, for the additional indicator we use the firms' (natural logarithm) asset size $\left(S I Z E_{i}\right)$.

\subsection{Definition of the firm}

As no information is available at what level allowance trade is managed within firms (e.g. centralized or decentralized), any allowance management structure we assume may be correct for some firms but inadequate for others. ${ }^{10}$ We aggregated firm-specific data

\footnotetext{
${ }^{9}$ Our selection of industry classification (NACE)-codes are the following. (1) 'coal': 'Mining of hard coal', 'Mining of lignite', and 'Extraction of peat'; (2) 'electricity': 'Electric power generation, transmission and distribution', 'Production of electricity', 'Transmission of electricity', 'Distribution of electricity', 'Trade of electricity', and 'Electricity, gas, steam and air conditioning supply'; (3) 'gas': 'Electricity, gas, steam and air conditioning supply', 'Extraction of natural gas', 'Manufacture of gas; distribution of gaseous fuels through mains', 'Manufacture of gas', 'Distribution of gaseous fuels through mains', 'Trade of gas through mains', and 'Extraction of crude petroleum and natural gas'; (4) 'petroleum': 'Extraction of crude petroleum', and 'Extraction of crude petroleum and natural gas'; (5) 'uranium': 'Mining of uranium and thorium ores', and 'Processing of nuclear fuel'; and (6) 'other': 'Steam and air conditioning supply', 'Wholesale of solid, liquid and gaseous fuels and related products', and 'Transport via pipeline'.

${ }^{10}$ Future research may be needed to show the impacts on these industry-structure trade-offs.
} 
over the following two 'dimensions': 1) per country, and 2) per Global Ultimate Owner (GUO). ${ }^{11}$ The reasoning for the country level is that EU ETS compliance is a national matter, and that most EU electricity markets are national. And as to the GUO-level, we consider it more likely that subsidiaries within the same country had a (nationally) coordinated allowance management rather than a decentralized one. ${ }^{1213}$ To indicate whether trades took place within GUOs, so that firms pool resources and thus behave autarkical, we create the dummy $S A M E G U O_{i, t}$ equalling 1 if firms trade among subsidiaries, and 0 if otherwise.

\subsection{Construction of trade variable}

For the allowance trade variable, we take the daily net trades and, to stabilize the variance, transform these through the natural logarithm. ${ }^{14}$ The dependent variable is thus as follows:

$$
\operatorname{TRADE} E_{i, t} \begin{cases}=0 & \text { if } W_{i, t}=0 \\ =\operatorname{sign}\left(W_{i, t}\right) \cdot \ln \left(\left|W_{i, t}\right|\right) & \text { if } W_{i, t} \neq 0\end{cases}
$$

where $W_{i, t}=P U R C H_{i, t}-S E L L_{i, t}$, and where $P U R C H_{i, t}$ and $S E L L_{i, t}$ are the allowance purchases and sales of firm $i$ at time $t$.

\footnotetext{
${ }^{11}$ GUOs are the 'ultimate' shareholders by controlling at least $50,01 \%$ of shares. With the Bureau van Dijk (BvD) database codes, the GUOs can be requested.

${ }^{12} \mathrm{An}$ example resulting from this two-level merge is that the UK subsidiary (i.e. the country) of GDF SUEZ (i.e. the GUO) contains all domestic energy production and UK-registered allowance trade from International Power Ltd. (and others, such as Cofely District Energy Ltd.). In the sample, GDF SUEZ operates in $13 \mathrm{EU}$ Member States. It therefore has 13 of such "separate" country-GUO entities.

${ }^{13}$ Furthermore, of the total number of identified firms (1549), 227 firms did not trade and were left out of the sample. They had been identified as they had at least one installation in the EU ETS National Allocation Plans. The regressions in Section 5 omit these firms automatically.

${ }^{14} \mathrm{As}$ firms are aggregated at the national and GUO-level (cf. Section sec:firmdef), allowance trades between national GUO-subsidiaries are netted out.
} 


\subsection{Production and emission-related determinants}

As electricity demand is at least partially uncertain, also the firms' allowance demand will be. With more installations, it is expected that autarkic firms are better able to meet electricity demand changes. To capture this production effect, we include the current monthly electricity demand $\left(E D E M_{i, t}\right)$, its change with respect to the previous month $\left(\triangle L E D E M_{i, t}\right)$, and the future month $\left(\triangle F E D E M_{i, t}\right) \cdot{ }^{15}$ Moreover, by having more diverse fuel-sourced installations, autarkic firms are expected to be better able at switching fuels. The propensity for switching fossil fuels is approached via the coal and gas price difference: $S P R E A D_{t}=\ln \left(C O A L_{t}-G A S_{t}\right)$. We further interact $S P R E A D_{t}$ with $B R O W N_{i, t}$, the fossil fuels share in electricity production, to get $B S P R E A D_{i, t}$. Fuel-switching is then more likely to occur with larger fuel price differences, and with higher fossil fuel proportions in the production of electricity. ${ }^{16}$

\subsection{Trade and hedge-related determinants}

Meeting the allowance demand from production and emissions can be costly if carbon price and volume risks are not accounted for. Hedging of these risks can minimize the adverse effects on the firms' optimal production decisions (e.g. Smith Jr. (2008)). To capture the financial drivers of carbon trading, we selected three variables. First, the 'cost of carry arbitrage' $\left(C C A_{t}\right)$ is a proxy for arbitrage opportunities. $C C A_{t}$ is the difference between the time-discounted carbon futures price minus the spot price, and reflects the opportunity costs of keeping allowances. If positive (negative), it is profitable to keep (sell) allowances, and hedge the risks on the derivatives market. $C C A_{t}$ may expose riskfree arbitrage possibilities, especially when the carbon market was relatively immature. Second, $B S S_{t}$ is a trade proxy on market timing. $B S S_{t}$ is the difference between the current carbon spot price and its 30-day moving average. If correctly followed, firms

\footnotetext{
${ }^{15}$ Daily electricity demand from ENTSO-E is available only from 2006. Furthermore, monthly data smoothes the volatile and non-linear nature of daily electricity production.

${ }^{16}$ Lacking the exact composition of fossil fuels at installation and (therefore) firm level, the switching price could not be estimated (e.g. as in Bertrand (2012)).
} 
should sell (purchase) allowances with positive (negative) spreads of $B S S_{t}$. Third, the 'bi-directional'-index $\left(B D I N D E X_{i, t}\right)$ is a proxy for the trade direction. While $T R A D E_{i, t}$ shows the daily net trade of a firm, $B D I N D E X_{i, t}$ captures whether this daily trade came about through purchases, sales, or a combination of both. BDINDE $X_{i, t}$ is defined as follows:

$$
B D I N D E X_{i, t} \begin{cases}P U R C H_{i, t} / Q_{i, t} & \text { if } P U R C H_{i, t}>S E L L_{i, t} \\ 0 & \text { if } P U R C H_{i, t}=S E L L_{i, t} \\ 0 & \text { if } P U R C H_{i, t}=S E L L_{i, t}=0 \\ (-1) * S E L L_{i, t} / Q_{i, t} & \text { if } P U R C H_{i, t}<S E L L_{i, t}\end{cases}
$$

where $Q_{i, t}=\left|P U R C H_{i, t}\right|+\left|S E L L_{i, t}\right| . \quad B D I N D E X_{i, t}$ reflects the proportion of purchases, $P U R C H_{i, t} / Q_{i, t}$ over the positive ranges $(0,0.5)$ and $(0.5,1]$, the proportion of sales, $S E L L_{i, t} / Q_{i, t}$ over the negative ranges $[-1,0.5)$ and $(-0.5,0)$, and equals zero if $P U R C H_{i, t}=S E L L_{i, t}$ or no trades occurred. In the terminology of Smith and Swierzbinski (2007), trades are 'uni-directional' or 'bi-directional' if $B D I N D E X_{i, t}$ approaches -1 and +1 or approaches 0 , respectively. Although we are limited in inferring whether firms hedge or not, we consider that 'bi-directional' traders are active at readjusting their allowance positions which, as such, is indicative of hedging.

\subsection{The compliance trajectory indicator}

The sample runs towards the end of EU ETS Phase I, when Phase I allowances became void for Phase II. We therefore consider that firms steer the trajectories of their allowance holdings so that these minimize any differences in their allocations and emissions. Indeed, firms having and therefore surrendering fewer allowances than emissions will be penalized. And, firms should redeem their surplus allowances. In essence, these compliance trajectories can thus be regarded as the outcome of a firm's production (and emissions) activity, their internal (i.e. within-conglomerate) allowance pooling, carbon trading and hedging, or a combination thereof. All these aspects are captured in the 
firms' management of their allowance holdings.

The only carbon allowance holdings estimates we found were in Martino and Trotignon (2013) on EU ETS totals, and in Hintermann (2013) at the electricity firm level, where both analyses concern Phase I, and are limited at the annual level. Hintermann (2013) includes the Phase I allowance holdings of several EU power firms and considers that, through excess holdings, firms may have forced upwards the carbon price in 2005 and 2006. Furthermore, Hintermann (2013) shows that most power firms gradually cut back their holdings before the end of Phase I but, surprisingly, some built up or kept sizeable amounts in stock. He considers some of these surpluses to be "too large for [them] to be explained by hedging against carbon risk". While our analysis accounts for the firms' trades and hedges, we do not test this conjecture as our focus is on the allowance trade amounts rather than the size of their allowance holdings. ${ }^{17}$

The compliance trajectory indicator $\left(L C T_{i, t}\right)$ is based on four main allowance factors: the emissions, allowances allocations, purchases, and sales. For the emissions we take the verified sum of emissions over Phase I. A firm will be formally certain on its emissions after an independent verifier has drawn up a monitoring report after a calendar year has passed. Given that energy production is typically booked ahead in future, we assume firms are able to obtain a bandwidth in which the Phase I cumulative emissions would end up. Based on these future emissions estimates, future allocations should be 'reasonably' predictable through the terms as laid out in the National Allocation Plans (NAPs). We therefore take the sum of the three allocations (to be) received over Phase I. It is up to firms to minimize any differences between their allocations and emissions through purchases and sales.

By construction, $L C T_{i, t}$ changes when firms trade allowances. Its lagged value is therefore selected to capture whether deviations from the compliance trajectory incen-

\footnotetext{
${ }^{17}$ At the end of Phase I, carbon prices were very low. That these allowance surpluses could not be transferred to the next EU ETS Phase may partly explain why firms held too many allowances.
} 
tivize firms to trade allowances. ${ }^{18} L C T_{i, t}$ is also defined at the conglomerate level, to prevent diverging values for firms pooling their allowances within conglomerates.

$L C T_{i, t}$ is constructed as follows:

$$
L C T_{i, t} \begin{cases}=0 & \text { if } Z_{j, t}=0 \\ =\operatorname{sign}\left(Z_{j, t}\right) \cdot \ln \left(\left|Z_{j, t}\right|\right) & \text { if } Z_{j, t} \neq 0\end{cases}
$$

with

$$
Z_{i, t}=\sum_{i \subset j}^{J}\left[A L L O C_{i}-E^{\prime} I S S_{i}+\sum_{t=1}^{T} P U R C H_{i, t}-\sum_{t=1}^{T} S E L L_{i, t}\right]
$$

and where subscript $j$ stands for the conglomerate which firm $i$ is part of, the variables $A L L O C_{i}$ and $E M I S S_{i}$ represent firm $i$ 's sum of Phase I allocations and verified emissions, respectively, and where $\sum_{t=1}^{T} P U R C H_{j, t}$ and $\sum_{t=1}^{T} S E L L_{j, t}$ are the cumulative allowance purchases and sales from $t=0$ to $t .{ }^{1920} L C T_{i, t}=0$ is the benchmark or equilibrium towards which firms are expected to move.

\section{Data and descriptive statistics}

We obtained data from different sources: EUTL, ENTSO-E, Orbis, Thomson Reuters Datastream, and Carma.org. Details on the construction of this dataset can be found in Appendix A. Table I provides an overview and a short description of the determinants as discussed in Section 3. This Section provides the descriptive statistics based on the sample clustering, as discussed in Section 3.1.

Table II shows the descriptive statistics on $T R A D E_{i, t}, L C T_{i, t}$, and the production

\footnotetext{
${ }^{18}$ This is analogous to Kerr and Maré (1999), where the trade decision depends on the trade value to be gained minus the transaction costs.

${ }^{19} \mathrm{~A}$ ratio would be less useful for $L C T_{i, t}$ since the four main factors can take up zero or positive values in all combinations. Also firms without allocations or emissions should have sold the allowances they had in stock at the end of Phase I.

${ }^{20} L C T_{i, t}$ implicitly takes allowance banking and borrowing into account.
} 
and emission-related determinants. The upper (lower) rows of the variables contain the means and standard deviations of the less (more) endowed or small (large) firms. That the $T R A D E_{i, t^{-}}$averages are close to zero is mainly the result from the many non-trades, but also from the fact that average purchases almost equalled average sales (not shown here). In general, large and endowed firms are purchasers (i.e. $T R A D E_{i, t}>0$ ); the small and less endowed ones are sellers. Exceptions, however, are the non-dispersed traders and the endowed non-electricity firms. Both groups sold about as much as their less-endowed or smaller counterparts.

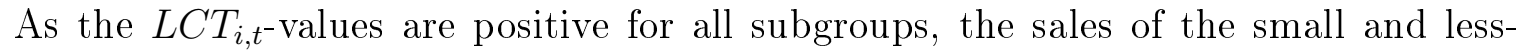
endowed firms, non-dispersed traders, and endowed non-electricity firms enable them to redeem their superfluous allowances. In contrast, the large and endowed firms are purchasing, and more than they need. They are thereby likely to trade allowances for purposes other than compliance.
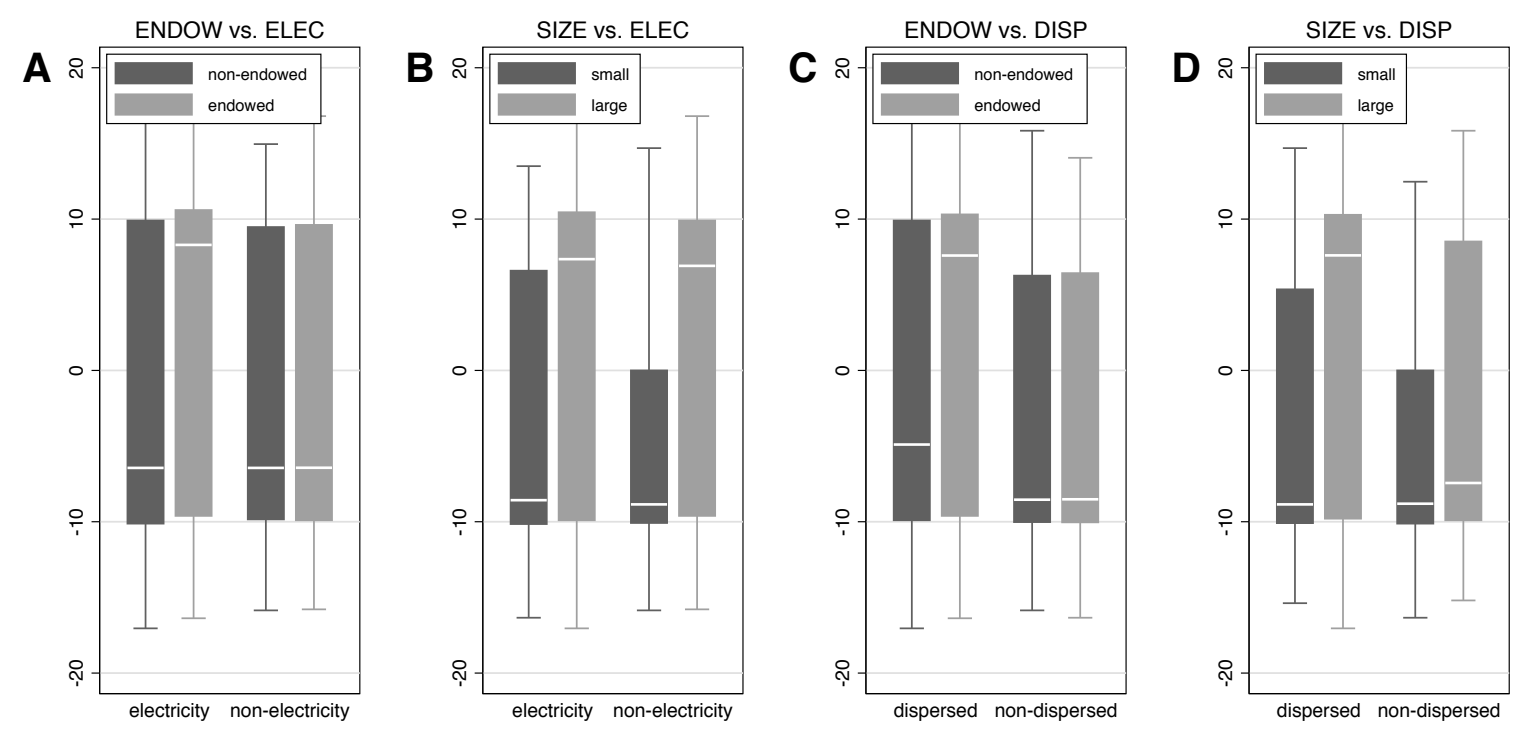

Figure 1: Box-and-whisker plots of $T R A D E_{i, t}$ over primary groups $E L E C_{i}$ and $D I S P_{i}$, and secondary groups $E N D O W_{i}$ and $S I Z E_{i}$.

Figure 1 plots $T R A D E_{i, t}$ within the two trade frequency subsets (Panel A and B: $E L E C_{i}$, Panel C and D: DISP ${ }_{i}$ ) and across the two autarky indicators (Panel A and C: $E N D O W_{i}$, Panel C and D: $\left.S I Z E_{i}\right)$. The darker-shaded box-plots encompass $T R A D E_{i, t}$ 
of the less-endowed or small firms, while the lighter-shaded plots encompass the TRADE $E_{i, t}$ of endowed or large firms. Again, the pattern emerges that large and endowed (small and less-endowed) firms are purchasers (sellers), and that the same three subgroup exceptions are sellers rather than purchasers. Yet, the plots emphasize that $S I Z E_{i}$ leads to clearer subgroup distinctions than $E N D O W_{i}$. For example, with the two $S I Z E_{i}$-subgroup exceptions, non-electricity (Panel B), and non-dispersed trade (Panel D), the interquartile ranges only span the negative quadrant. They therefore primarily sold allowances. For $E N D O W_{i}$, in contrast, all subgroups purchased and sold allowances. This difference arises, for example, for the non-electricity purchasers in Panels A and B. These firms' majorities purchased among the large firms' subgroup, but sold in the endowed firms' subgroup.
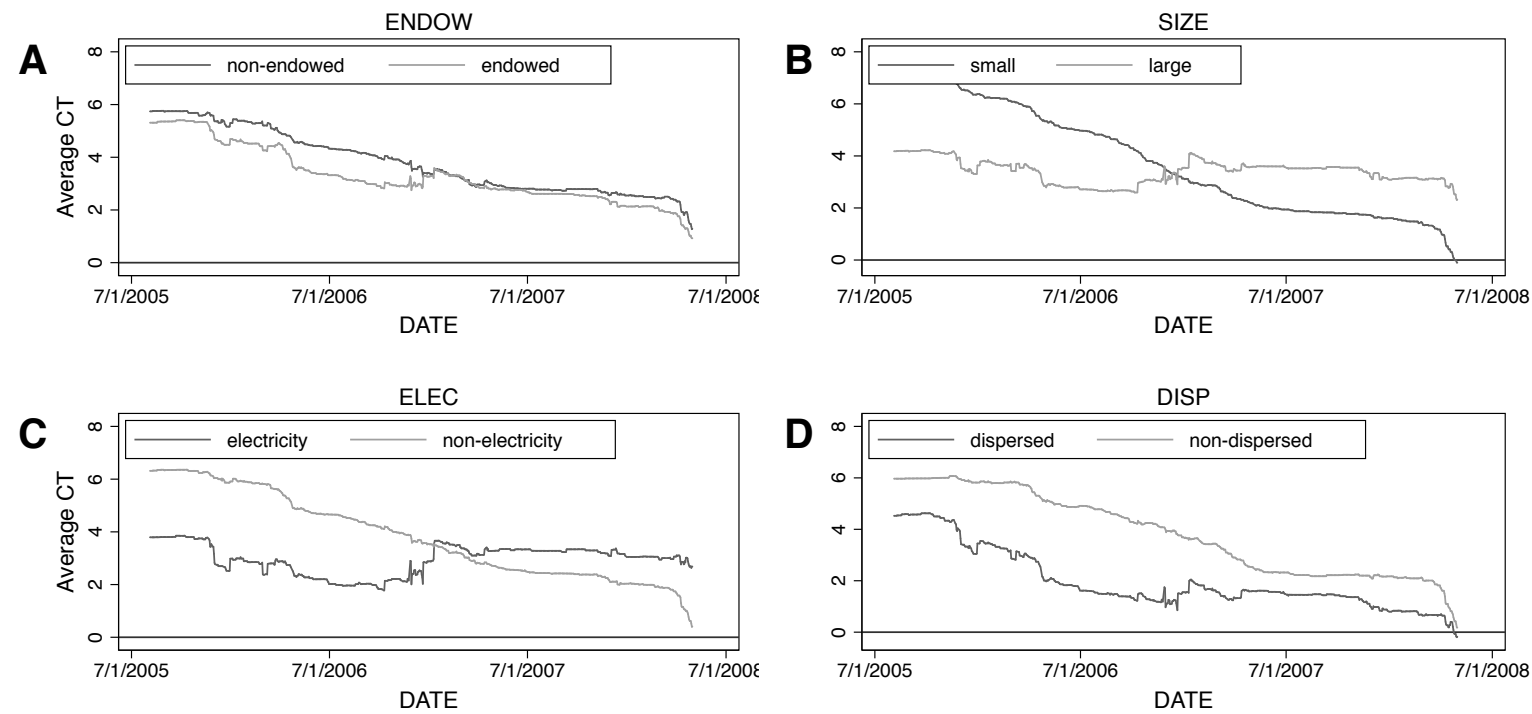

Figure 2: Compliance trajectory $\left(L C T_{i, t}\right)$ over time based on subgroups: endowed vs. less endowed (Panel A), small vs. large (Panel B), electricity vs. non-electricity firms (Panel C), and non-dispersed vs. dispersed traders (Panel D).

Figure 2 plots the subgroup differences on $L C T_{i, t}$ over time. As mentioned above, $L C T_{i, t}$ should converge to zero 1) to prevent penalties when having too few allowances in stock, and 2) to redeem superfluous allowances. For $E N D O W_{i}$ (Panel A), small firms (Panel B), non-electricity firms (Panel C), and DISP $P_{i}$ (Panel D), $L C T_{i, t}$ converges gradually, despite some $L C T_{i, t}$-plateaus over the sample period considered (e.g. over 
2007). Differences in $E N D O W_{i}$ are (again) not pronounced, while they are salient for the others. Interestingly, $L C T_{i, t}$-levels of non-electricity firms and non-dispersed traders were swiftly lowered in the last weeks of Phase I. Apparently, their final Phase I demand became certain, which triggered them to redeem their superfluous allowances. Yet, $L C T_{i, t}$-levels of large-sized and electricity firms fluctuate around a value of 3, and hardly reduce their allowance holdings. ${ }^{21}$

Table II further shows the production and emission-related determinants. As to the fuel inputs used, we assumed all firms follow the same EU-wide gas and coal price indices. This results in an equal average coal-gas price differential $\left(S P R E A D_{t}\right)$ for all firms $(3,776)$. BSPREAD $D_{i, t}$, however, is generally larger for large and endowed firms. Being a multiple of $S P R E A D_{t}$ and $B R O W N_{i, t}$, the large and endowed firms thus had higher fossil fuel percentages for their electricity production. ${ }^{22}$ Moreover, no sizeable subset differences can be observed for $\triangle L E D E M_{i, t}$ and $\triangle F E D E M_{i, t}$, primarily because their underlying data is country-specific. That large and endowed firms have larger $E D E M_{i, t^{-}}$ values may result from them operating in national markets with higher MWh-demands (i.e. the larger EU Member States).

Table III shows the trade and hedging determinants. $B S S_{t}$ and $C C A_{t}$ do not differ over the subsets (i.e. as with $S P R E A D_{t}$ ). These are EU-wide and assumed to be faced by all firms. If $B S S_{t}$ is correctly followed, firms should sell (purchase) allowances with positive (negative) spreads of $B S S_{t}$. Given its negative value, the average signal has thus been to purchase allowances. Moreover, the $C C A_{t}$-averages are lower than the standard deviations. This wide range of $C C A_{t}$ close to zero makes it likely that allowance arbitrage did not always incentivize firms to trade. Moreover, $B D I N D E X_{i, t}$ is positive for most $E N D O W_{i}$ setups, but negative for most small firms. Interesting with $B D I N D E X_{i, t}$ is that the large and endowed firms' standard deviations are typically larger, and are paired

\footnotetext{
${ }^{21}$ Hintermann (2013) provides a discussion on this observation why, towards the end of Phase I, electricity firms kept sizeable amounts of allowances in stock.

${ }^{22}$ By definition, $B R O W N_{i, t}$ is missing for non-electricity firms. As we force $B R O W N_{i, t}$ to zero for these firms explains the $B S P R E A D_{i, t}$-zeroes for the two non-electricity subsets.
} 
with higher means. These higher standard deviations are especially found for electricity firms. By spanning far into the positive and negative ranges, these firms' trades are likely to have served hedging purposes. Finally, $S A M E G U O_{i, t}$ is generally larger for the large and endowed firms. That more intra-conglomerate trade is conducted among the endowed or large firms accords with autarkic behaviour.
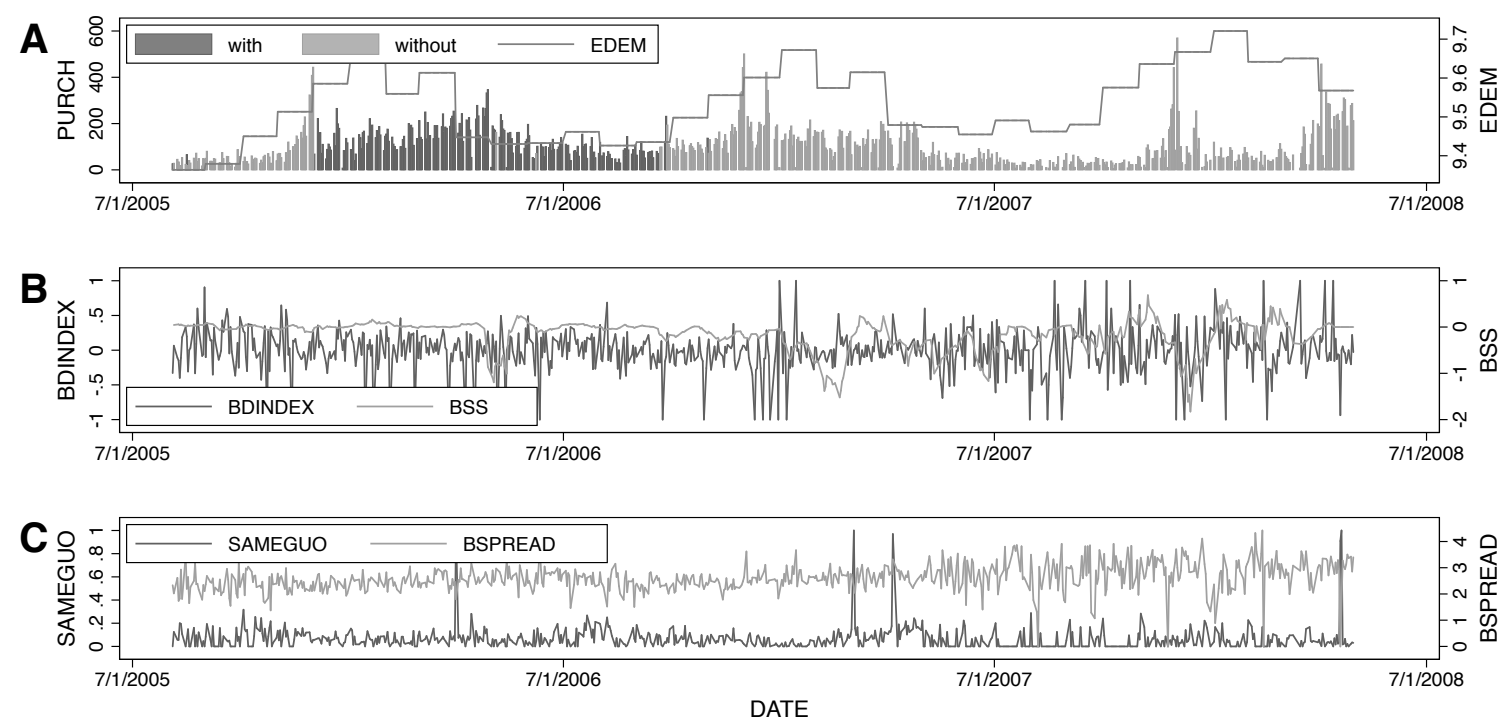

Figure 3: Panel A shows electricity demand (EDEM), and the purchased amounts $(P U R C H)$ which are dark (light)-shaded if $C C A_{t}>0.05(<0.05)$. Panel B shows the bi-directional index $(B D I N D E X)$ and the buy-and-sell signal $(B S S)$. Panel $\mathrm{C}$ shows the within-conglomerate transactions $(S A M E G U O)$, and the interaction of the fossil fuel proportion with the coal-gas price spread $(B S P R E A D)$.

Figure 3 plots the trade and hedging-related determinants over time. Panel A shows that allowance purchases $(P U R C H)$ follow three recurring patterns. ${ }^{23}$ First, volumes spike at year's end: when carbon derivatives are exercised and firms need to file their bookkeeping. Second, volumes take up gradually from January towards April when (previous calendar year's) allowance demand is verified, and allowances are exchanged before the annual end-of-April allowance surrender deadline. Third, the plotted allowance volumes generally move in tandem with (lagged) national electricity demand. For example, allowance volumes are low during the third quartiles, when less electricity is required for

\footnotetext{
${ }^{23}$ The allowance sales follow a similar pattern (not shown in Figure 3).
} 
the summer months. ${ }^{24}$ The figure further shows that $C C A_{t}$, which combines carbon spot and futures prices, was significant before April, 2006. After April, 2006, it became publicly known that aggregate allowance demand was much lower than expected. This led to a downfall of the carbon price (see e.g. Jong et al. (2014) and Zeitlberger and Brauneis (2014)), and subsequent lower prices towards the end of Phase I. With $C C A_{t}$ lower than 0.05, transaction costs may prevent firms from exploiting arbitrage opportunities.

The BDINDEX $X_{i, t^{-}}$spikes in Panel B of Figure 3 show that purchases and sales comove over time. This is the case even if $B S S_{t}$, the buy-sell signal, revolves around zero. Over 2007 and 2008, the BDINDE $X_{i, t}$-spikes became gradually more responsive to $B S S_{t}$. Around that time, $C C A_{t}$ moved below 0.05 , which may have led indicators as $B S S_{t}$ to increase in importance.

Finally, Panel $\mathrm{C}$ of Figure 3 shows that $S A M E G U O_{i, t}$ and $B S P R E A D_{i, t}$ move opposite to one another, which accords with autarkic behaviour. Gas price increases (BSPREAD $D_{i, t}$ moves down) increase demand for allowances as coal, being more carbonintensive, becomes relatively more attractive. This higher allowance demand incentivizes firms to pool their allowances internally ( $S A M E G U O_{i, t}$ moves up).

\section{Empirical results and discussion}

While applying $E N D O W_{i}$ and $S I Z E_{i}$ as interaction terms within the subsets of $E L E C_{i}$ and $D I S P_{i}$, the econometrics tests we ran point towards the use of panel data models which account for autocorrelated, heteroskedastic, and panel-correlated structures of the error term. ${ }^{25}$ We therefore selected a fixed effects model with Driscoll-Kraay standard errors, and a random effects model with panel-corrected Prais-Winsten standard

\footnotetext{
${ }^{24}$ During these months, trade activity is lower in general. Besides the April and December EU ETS volume spikes, this pattern may also be driven by institutional factors.

${ }^{25}$ The Breusch-Pagan LM test rejected the pooled model, the panel data Wooldridge test for autocorrelation rejected the null of no first-order autocorrelation, while the modified Wald statistic rejected the null of group-wise homoskedasticity.
} 
errors. ${ }^{26}$ If the Hausman test rejected the random effects model, we selected the DriscollKraay fixed effects model, and the Prais-Winsten random effects model if otherwise. ${ }^{27}$

Table IV shows the regression results. The lower rows (i.e. coefficients (3b) to (16b)) contain the interaction terms for firms which are less endowed (columns 2 to 5) and small (columns 6 to 9 ). These coefficients indicate the average $E N D O W_{i}$ or $S I Z E_{i}$ slopedifferences, relative to the base coefficients (3a) to (16a). The intercept impacts from $E N D O W_{i}$ or $S I Z E_{i}$ (i.e. relative to the constant term) are provided by coefficients (1) and (2). Furthermore, the upper rows of Table $\mathrm{V}$ provide the joint significance Wald tests on the base and interaction terms, whereas the lower rows provide the joint significance Wald tests on the interaction terms only.

The match of the fitted values with the dependent variable varies widely (R-squared: from 0.248 to 0.648 ). As the lowest fits are found for the electricity firms, their determinants to trade may be based on different or more refined criteria. Furthermore, all setups with $S I Z E_{i}$ result in better R-squared values than with $E N D O W_{i}$. This difference may result from the more developed measurement of total assets (e.g. through accounting standards). ${ }^{28}$ For the results discussion below, we opted for the $S I Z E_{i}$-interaction term. Indirectly, this analysis will therefore contribute to the transaction costs literature, which posits that both EU ETS implementation and trading costs are declining in firm size (e.g. Jaraitè et al. (2010)).

\subsection{Compliance trajectory}

Since firms are expected to minimize their allowance holdings, positive (negative)

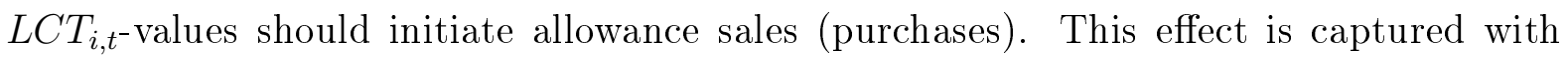

\footnotetext{
${ }^{26}$ We also considered feasible generalized least squares models with correlated disturbances but, unfortunately, we abandoned it after Stata 12 was unable to provide results.

${ }^{27}$ As the Prais-Winsten model allows for different autocorrelation structures, the ones with the best R-squared fits were selected. These autocorrelations are common- or panel-specific, and via time-series or Durbin-Watson setups. For the Driscoll-Kraay models, the default lag order of autocorrelation was selected.

${ }^{28}$ With future research, the fit of $E N D O W_{i}$ may improve with different underlying composite indicator variables.
} 
negative $L C T_{i, t}$-coefficients signs. Table $\mathrm{V}$ indicates $L C T_{i, t}$ and $L C T_{i, t}^{2}$ are significant. For large electricity firms, for example, $L C T_{i, t}$ decreases $T R A D E_{i, t}$ with $-0,001 \% .{ }^{29}$ But due to the quadratic $L C T_{i, t}^{2}, L C T_{i, t}$ changes sign when it crosses a value of $-\beta_{L C T} /(2 *$ $\left.\beta_{L C T_{i, t}^{2}}\right)=-0,5$. It is intuitive that $L C T_{i, t}$ is negative over most of the negative quadrant, as negative $L C T_{i, t}$-levels result in non-compliance. Less intuitive is the accumulation of allowance holdings after this threshold is reached.

Even if significant, the small $L C T_{i, t^{-}}$values have low predictive impacts on the amounts traded. In calculating $L C T_{i, t}$, however, one possible weakness concerns the assumed fixed emissions. As emissions are likely to be a function of production, $E D E M_{i, t}$ may capture part of the $L C T_{i, t^{-}}$ariance.

\subsection{Production and emissions}

Overall, firms are expected to sell allowances if coal (gas) prices increase (decrease), and more so if the fossil fuel percentage $\left(B R O W N_{i, t}\right)$ in electricity production is larger. Coefficients should thus be negatively valued. Except for non-electricity firms whose $B R O W N_{i, t}$ and, therefore, BSPREAD $D_{i, t}$ is zero (cf. Table ??), SPREAD is positive and therefore contradicts this expectation. On average, allowance purchases are conducted with coal (gas) price increases (decreases). ${ }^{30}$ Of further interest is that the small firms' slopes are negative and small. Although outside the scope of this paper, 'delta hedging' may explain these trade behaviour differences regarding the gas and coal prices. ${ }^{31}$ If small firms follow the expected approach, it may imply they have not applied this hedging technique. These observations on $B S P R E A D_{i, t}$ would thus actually be relevant for the "Trade and hedging" section below.

Electricity demand is expected to be positively related to allowance purchases, as

\footnotetext{
${ }^{29} \mathrm{As} T R A D E_{i, t}$ and $L C T_{i, t}$ are in logarithmic terms, the coefficients need to be considered as elasticities.

${ }^{30}$ The smaller coefficient of $B R O W N_{i, t}$, albeit in line with expectations, will not make up for the impact from $S P R E A D_{t}$.

${ }^{31}$ We are grateful to Mohammed R. Osman for mentioning this hedging type after having attended our presentation at the 2014 Energy Systems Conference in London.
} 
higher electricity demand necessitates more energy production and, hence, allowance demand. The three electricity demand variables are only jointly significant for the electricity firms and the dispersed traders. Impacts from $E D E M_{i, t}$ also come from $\triangle L E D E M_{i, t}$ and $\triangle F E D E M_{i, t}$, which impact $E D E M_{i, t}$ positively and negatively, respectively (cf. Table I). $E D E M_{i, t}$ will then be positive for all setups, but negative yet small for small electricity firms. The latter coefficient is relevant for allowance sales, as Figure 1 shows that small firms were predominantly selling. It is thus likely that these firms took electricity demand uptakes as opportunities to sell even more allowances.

\subsection{Trade and hedging}

Expected is that subgroups with $B D I N D E X_{i, t^{-}}$coefficients close to zero traded 'bidirectionally'. If so, their trades will be indicative of hedging. In all setups, $B D I N D E X_{i, t^{-}}$ slopes are positive, while more so for small firms, but less so for large firms and nondispersed traders. ${ }^{32}$ That non-dispersed traders trade bi-directionally is counter-intuitive, and most likely results from $B D I N D E X_{i, t}$ equalling zero for non-trades. To separate the bi-directionality from the low-trade frequency, we use the Table III means and standard deviations to calculate the covariances (not shown here). High standard deviations are indicative of varied trades and, hence, bi-directionality. Although the large-sized nondispersed traders have high standard deviations, their covariances are among the lowest, which likely results from their low trade frequencies. By pairing the covariances and standard deviations, the dispersed traders and electricity firms subgroups rank highest, a result in line with intuition.

If $B S S_{t}$ is correctly followed, firms should sell (purchase) allowances with positive (negative) spreads of $B S S_{t}$. $B S S_{t}$ is only significant for non-electricity firms at a $95 \%$ confidence level. The coefficient is negative and positive yet small for large and small firms, respectively. The large firms thus follow $B S S_{t}$ as conjectured. An explanation for

\footnotetext{
${ }^{32}$ By construction, BDINDE $X_{i, t}$-slopes cannot be negative; if $T R A D E_{i, t}$ is positive, the daily amounts purchased dominate the amounts sold, which results in a positive $B D I N D E X_{i, t}$, and vice versa. And, the sample only consists of firms which traded, so the slope cannot be zero.
} 
the small firms' positive coefficient is that they were selling, while $B S S_{t}$ was predominantly negative.

Furthermore, expected for $C C A_{t}$ is that higher levels incentivize firms to trade with risk-free arbitrage possibilities. Yet, this indicator did not significantly impact any subgroup within $S I Z E_{i}$, which may stem from the low $C C A_{t}$-levels as of end-2006 (e.g. see the discussion for Figure 3). That at the same time $B S S_{t}$, a shorter-term trade indicator than $C C A_{t}$, became increasingly responsive is indicative of the carbon market becoming more liquid and efficient.

Further attested by their low BDINDE $X_{i, t^{-}}$values (and the possible delta-hedging with $S P R E A D_{t}$ ), the large firms, dispersed sellers, and electricity firms are thus most active at allowance hedging. Being less restricted in autarky terms than small firms, they would actually be expected to hedge less. Interesting for further research is whether the trades by the small firms could have been more profitable if they followed $B S S_{t}$, and why they did not follow it. It could be that they faced a steeper learning curve regarding the carbon market (i.e. resulting in a lower $B D I N D E X_{i, t}$ ).

If firms are to behave autarkical, they are expected to purchase (sell) more within their conglomerates than they are purchasing (selling). Given that all $S A M E G U O_{i, t^{-}}$ subgroups are significant, we paired their $T R A D E_{i, t}$-averages (cf. Table II) with their $S A M E G U O_{i, t}$-regression coefficients. We find that the average impact of moving from the subgroup $S A M E G U O_{i, t^{-}}$average to $S A M E G U O_{i, t}=1$ is always opposite to the subgroup's $T R A D E_{i, t^{-}}$average. In other words, if a subgroup's $T R A D E_{i, t^{-}}$average is to purchase, then it is selling within conglomerates, and vice versa. ${ }^{33}$ This result accords with firms applying a centralized management in allocating their allowances. Yet, it does not accord with autarkic behaviour, where additional allowances are purchased from or sold to the carbon market. Since allowance trade is cost-effective with more

\footnotetext{
${ }^{33} \mathrm{As}$ discussed in Section 3.2, one of the impacts from aggregating firms at country-level is that within-conglomerate trades occurring within the same country were netted out. SAMEGUO $i, t$ may thus change if a different allowance management structure is assumed for the sample.
} 
heterogeneity in pollution abatement potential, one implication from this non-autarkic behaviour may be that the abatement potential within conglomerates is lower than across the carbon market. It may also be that within-conglomerate transaction costs hinder firms in redeeming their mutual abatement heterogeneities (e.g. Stavins (1995)). The coordination of abatement through the carbon market will then prove to be more costeffective. This finding will then affirm that, next to the US Acid Rain Program (e.g. Ellerman et al. (2000)), the EU ETS leads to relative cost savings, for example, compared to a command-and-control system.

The $Q U A R T E R$ dummies hardly corroborate the annual recurring patterns of Figure 3. Most base coefficients are negative, so relative to the third quarter (i.e. the reference group), large firms are selling more (e.g. as in Table II). Coefficients are smaller or turn positive through the interaction terms, implying that small firms sell less and/or purchase relative to the third quarter. Finally, during the second quarter, relatively fewer sales or more purchases take place. This result may be due to the second quarter containing the month of April, during which allowances are surrendered for compliance with the EU ETS.

\section{Conclusion}

Which EU ETS and energy industry factors determined the allowance amounts traded by energy firms over EU ETS Phase I (2005-2007)? Expected is that cost-minimizing firms first try to behave 'autarkical' by smoothing production and emissions and, hence, carbon costs within firm boundaries, which means that firms will trade and hedge less on the carbon market. Relatively more purchases (sales) are then conducted across subsidiaries than on the market. The subsequent expectation is that over time, and towards the end of Phase I, firms follow their 'compliance trajectory'; by adjusting their allowance holdings to minimize any differences between their allocations and emissions.

Through a sample of EU energy firms' production and emissions characteristics, al- 
lowance transactions, and carbon and energy market prices, the firms were divided into subsets based on two trade frequency proxies: 1) whether firms conducted dispersed or non-dispersed trades, and 2) produced electricity or not. To test for autarky-differences, the variables were interacted with two indicators: a) endowed versus less endowed, through a composite indicator on the number and diversity of installations, and b) small versus large, based on asset size. By applying panel econometrics on these subgroups, we tested for the allowance trade responsiveness to EU ETS and energy industry factors. We selected the size-dichotomy as a proxy for autarkic behaviour, as it provided better regression fits.

First, our results show that, despite the electricity firms' under-allocations, all subgroups held more allowances than they needed, a likely result from the Phase I allowance oversupply (or demand shortage). The carbon market activity of non-autarkic firms is limited to selling off allowance surpluses. As such, they were actually following their compliance trajectory and behaving autarkical. Not following this trajectory were the autarkic firms, both non-electricity and electricity firms, by purchasing more than they needed. While precautionary purchases are understandable for electricity firms, which were made short in allowances by their Member States, future research must therefore explain why non-autarkic electricity firms were selling instead, and why autarkic non-electricity firms were over-purchasing allowances as well. Second, especially these 'over-purchasing' firms were driven by other EU ETS factors. They followed national electricity demand, and actively hedged on the carbon market. Opposite to expectations, electricity firms obtained allowances during higher coal and/or lower gas prices. This result may be due to (delta) hedging, an interesting conjecture for future research. Finally, all firms which purchased (sold) allowances on the carbon market were selling (purchasing) within their firm boundaries. This behaviour is not considered autarkic, and indicates that energy firms have a centralized management of allocating allowances. It also indicates that the abatement potential within conglomerates, especially in autarkic firms, may be higher across the carbon market than within firm boundaries, or the coordination of abatement 
may be more cost-effective through the carbon market. If so, this finding affirms that the EU ETS leads to relative cost savings, especially for the autarkic firms which may have further reduced their costs by actively hedging on the carbon market.

\section{References}

Alberola, E., Gloaguen, O., 2013. Climate and energy policies in the EU: A major role in reducing CO2 emissions from the energy and industry sectors. Tendances Carbone: The European carbon market monthly bulletin 84 .

Bertrand, V., 2012. Understanding fuel switching under the EU ETS. International Journal of Global Energy Issues 35, 494-517.

Considine, T.J., Larson, D.F., 2006. The environment as a factor of production. Journal of Environmental Economics and Management 52, 645-662.

Daskalakis, G., Psychoyios, D., Markellos, R.N., 2009. Modeling CO2 emission allowance prices and derivatives: Evidence from the european trading scheme. Journal of Banking \& Finance 33, 1230-1241.

Ellerman, A.D., Buchner, B.K., Carraro, C., 2007. Allocation in the European Emissions Trading Scheme. Rights, rents and fairness. Cambridge University Press, New York.

Ellerman, A.D., Joskow, P.L., Schmalensee, R., Montero, J.P., Bailey, E.M., 2000. Markets for clean air. The US acid rain program. Cambridge University Press, UK.

Ellerman, A.D., Montero, J.P., 2007. The efficiency and robustness of allowance banking in the US acid rain program. The Energy Journal 28, 47-71.

Hamilton, L., 2013. Statistics with STATA: Updated for Version 12. Brooks/Cole, Cengage Learning, Boston, MA, USA.

Hanemann, M., 2010. Cap-and-trade: A sufficient or necessary condition for emission reduction? Oxford Review of Economic Policy 26, 225-252.

Hintermann, B., 2013. Market power in emission permit markets: Theory and evidence. CESIFO working paper series 4447. 
Jaraite, J., Convery, F., Di Maria, C., 2010. Assessing the transaction costs of firms in the EU ETS: Lessons from Ireland. Climate Policy 10, 190-215.

Jaraitè, J., Di Maria, C., 2012. Efficiency, productivity and environmental policy: A case study of power generation in the EU. Energy Economics 34, 1557-1568.

Jaraitè, J., Jong, T., Kažukauskas, A., Zaklan, A., Zeitlberger, A., 2013a. Matching EU ETS accounts to historical parent companies: A technical note. Technical Report. European University Institute, Florence.

Jaraitè, J., Jong, T., Kažukauskas, A., Zaklan, A., Zeitlberger, A., 2013b. Ownership Links and Enhanced EUTL Dataset. Technical Report. European University Institute. Jaraitė, J., Kažukauskas, A., 2012. Firm trading behaviour and transaction cost in the European Union's Emission Trading System: An empirical assessment. CERE Working Paper 9 .

Jong, T., Couwenberg, O., Woerdman, E., 2014. Does the EU ETS bite? An event study. Energy Policy 69, 510-519.

Kerr, S., Maré, D., 1999. Transaction costs and tradable permit markets: The United States lead phasedown. Manuscript, Motu Economic and Public Policy Research, New Zealand .

Kreutzer, J., 2006. Cap and trade: A behavioral analysis of the sulfur dioxide emissions market. NYU Annual Survey of American Law 62, 125-162.

Maeda, A., 2004. Impact of banking and forward contracts on tradable permit markets. Environmental Economics and Policy Studies 6, 81-102.

Martino, V., Trotignon, R., 2013. Back to the future: A comprehensive analysis of carbon transactions in Phase 1 of the EU ETS. Les Cahiers de la Chaire Economie du Climat, Information and debates Series 27.

Rousse, O., Sevi, B., 2007. The impact of uncertainty on banking behavior: Evidence from the US sulfur dioxide emissions allowance trading program. Water, Air, \& Soil Pollution: Focus 7, 559-571. 
Semykina, A., Wooldrige, J., 2010. Estimating panel data models in the presence of endogeneity and selection. Journal of Econometrics 157, 375-380.

Smith, S., Swierzbinski, J., 2007. Assessing the performance of the UK emissions trading scheme. Environmental Resource Economics 37, 131-158.

Smith Jr., C.W., 2008. Managing corporate risk. In "Handbook of corporate finance" (B. E. Eckbo, Ed.). volume 2. US: North-Holland, Elsevier.

StataCorp, 2011. STATA Multivariate Statistics Reference Manual, Release 12. Stata Press. Texas.

Stavins, R., 1995. Transaction costs and tradeable permits. Journal of Environmental Economics and Management 29, 133-148.

Swinton, J.R., 2004. Phase I completed: An empirical assessment of the 1990 CAAA. Environmental and Resource Economics 27, 227-246.

Zaklan, A., 2013. Why do emitters trade carbon permits? Firm-level evidence from the European emission trading scheme. DIW Discussions Papers 1275, 1-32.

Zeitlberger, A., Brauneis, A., 2014. Modeling carbon spot and futures price returns with GARCH and Markov switching GARCH models. Central European Journal of Operations Research (forthcoming).

\section{Appendix A. Supplemental information on the dataset}

\section{Appendix A.1. Sources of data and details on matching}

First, we obtained the Phase I (2005-2007) National Allocation Plans (NAPs) and the transactions from the European Transaction Log (EUTL). Most corporate owners of the EUTL accounts were identified by the "Ownership Links and Enhanced EUTL Dataset" through their Bureau van Dijk's (BvD) company codes. ${ }^{34}$ Second, data on electricity

\footnotetext{
${ }^{34}$ This is a joint effort by researchers from different EU-based universities. The data set (Jaraite et al. (2013b)) as well as the technical report (Jaraitė et al. (2013a)) are available at the Climate Policy Research Unit website of the European University Institute (EUI).
} 
production (in MWh) was obtained via Carma.org at installation level; the fuel inputs percentages were only available at firm-level. ${ }^{35}$ And since Carma.org provides the 2004, 2009, and "future" electricity production, the installations' MWh-values over 2005 to 2007 were linearly extrapolated. Third, at BvD-level, we obtained the NACE Rev. 2 primary and secondary codes. The codes and, hence, the firms were selected if they were active in the electricity value chain (cf. footnote 9 in page 6). Aggregation of the variables was then performed through country-GUO pairs (cf. Section 3.2). ${ }^{36}$ Moreover, GUO-country firms were linked up with monthly national electricity demand, obtained via the ENTSOE country packages. ${ }^{37}$ The (EU-wide) time-series data is obtained from Datastream: the gas price (London Natural Gas Index), carbon prices (EEX-EU spot, and ICE Phase I average continuous futures ), and coal (Global Coal New Castle Index).

\section{Appendix A.2. Limitations of EUTL data}

Transactions from the EUTL are the settlements as recorded in the EU ETS allowance registries. A limitation is that the EUTL only provides the names of the purchasing and selling parties, the amounts settled, and the time-stamp of the settlement, but not the underlying price and the nature of the contract. This makes it almost impossible to distinguish spot transactions from (Over-the-Counter (OTC) or exchange-based) derivatives which initiated, intermediated, and finalized the EUTL settlements. ${ }^{38}$

Forwards and futures allow firms to flexibly up or downgrade the exposure they consider optimal. For example, exposure can be lowered by adjusting it with the corresponding derivative positions (e.g. going long while maintaining an overall short posi-

\footnotetext{
${ }^{35}$ Carma.org provides the corporate owners of the installations. We have linked up these companies with the BvD codes, as done with the EUTL accounts.

${ }^{36}$ The total assets are averaged over 2004-2009. More years are included than the sample scope (i.e. Phase I) due to year gaps for several companies (e.g. only 2005 and 2007 but not 2006), or if the data started later (e.g. at 2006 instead of 2005). Moreover, total assets could have been requested at the GUO-level, but that would have incorporated asset values outside of the EU.

${ }^{37}$ ENTSO-E historical monthly data was not available for Latvia, Lithuania, and Sweden.

${ }^{38} \mathrm{An}$ indication on the delivery of futures can be obtained by identifying the trade activity of EUTL exchange clearing accounts (Martino and Trotignon (2013)), but since most Phase I trade took place OTC, this identification would capture a small share of futures trades).
} 
tion) whereby exchanges of allowance ownership can be cancelled. EUTL transactions are allowance ownership exchanges, which must have been beneficial to both transacting parties. We therefore assume that these EUTL transactions are spot trades. But without the initiated and intermediated transactions, the net benefits of the "unobserved" observations (i.e. the latent demand) cannot be estimated. As inferences on the firms' decision to trade are difficult to make, we are limited in estimating the volume and sign of the observed transactions only. ${ }^{39}$ This further implies that dynamic panel data approaches would be of limited use (e.g. to capture delayed carbon or energy market shocks).

\section{Appendix A.3. Construction of ENDOW-indicator}

Table I lists the variables for $E N D O W_{i}$. Through these variables, we aim to capture the extent to which firms are endowed, and thus able to flexibly adjust their carbonintensity. GINIFUEL04 ${ }_{i}$ and GINIFUEL09, are variants to the well-known GINIcoefficient. ${ }^{40}$ It ranges from zero (one) for an equally (unequally) spread fuel type distribution. Besides $B R O W N_{i, t}$, this GINI-distribution is based on three other fuel input categories (as available in Carma.org): $H Y D R O_{i, t}, N U C L E A R_{i, t}$, and $R E N E W A B L E_{i, t}$. These categories are proportions which sum up to one. Furthermore, GINISECTOR ranges from zero (one) for an equal (unequal) intra-conglomerate producer type distribution. These suppliers are categorized via the industries: gas, coal, uranium mining and processing, petroleum, and "other".

Composite indicators capture the variance of the variables they are composed of. Through factor analysis, indices can be constructed from a "number of variables [...] by describing linear combinations [called: factors] of the variables that contain most of the information [i.e. the variance]" (StataCorp (2011)). Since weights (or: 'loadings') on the

\footnotetext{
${ }^{39}$ If the decisions to trade are separate from the decisions what amounts to exchange, estimates would be inconsistent if the decision to trade is not random. We estimated the likelihood of allowance trade via a (panel data) approach from Semykina and Wooldrige (2010). The inverse Mills ratios were jointly insignificant. It is not clear-cut, however, which variables affect the trade decision as they may impact the amounts decision as well.

${ }^{40}$ The "04" and "09" for GINIFUEL are related to Carma.org, which only provides details over 2004, 2009, and "future" (cf. Section Appendix A.1)
} 
variables differ, increases in one variable may translate into higher $E N D O W_{i}$-values than for others. ${ }^{41}$

$E N D O W_{i}$ was calculated for two separate subsets based on $E L E C_{i}$ (cf. Section 3.1), so that the index for electricity firms is based on more variables. Table A.I contains the principal factors (panel A), and the factor loadings with its unique variances (panel B). ${ }^{42}$ Panel A shows that the electricity and non-electricity firms' eigenvalues (EV) of the fourth and first factor are less than one, respectively. The corresponding numbers of factors have therefore been selected. ${ }^{4344}$ Panel B contains the factor loadings; the coefficients that make up the above mentioned linear combinations. For the electricity firms, the second factor (F2) was selected. It explained less than factor 1 (a 7\% difference), but its coefficients were more in line with the theory. Autarkic firms are expected to have lower Gini-factors, while the other factors are expected to be positively related. Also the factor 1 (F1) loadings for non-electricity firms are in line with the theory.

After standardizing the index values, the two subsets were merged into one overall index. Since the indicator variable is negative for some but positive for others, the index-values were min-max normalized. We subsequently set up the dummy $\left(E N D O W_{i}\right)$ equalling 1 for firms with index-values above the sample median, and 0 otherwise.

\footnotetext{
${ }^{41}$ Composite indicators are typically constructed via Principal Component Analysis (PCA) and Factor Analysis. Among Factor Analysis methods, "Principal factoring with iterated communalities (IPF) identifies the underlying dimensions that best account for the pattern of correlations between variables" (Hamilton (2013)). As the variables are correlated (not shown here) and PCA does not take up intervariable 'communalities', we selected IPF as the factor analysis method.

${ }^{42}$ The variables from both subsets were checked whether they have enough in common, so that a factor model would be warranted. Only for the non-electricity firms do a couple of variables have low squared multiple correlations values, warranting possible exclusion. However, both subsets have "middling" Kaiser-Meyer-Olkin values, and both subsets' anti-image correlation coefficients are low. Low-dimensional reduction of the data would thus be possible.

${ }^{43}$ Iterated principal factors estimations depend on the number of retained factors.

${ }^{44}$ Indeed, the values of 1 in the proportion column ("Prop.") indicate that these factors result in a full coverage of the variance.
} 
Appendix A.4. Details on the trade frequency and autarky clusters

Figure A.1 shows the distribution of firms over the categories of trade frequency (the x-axes) and autarky (the y-axes). Differences between the box-and-whisker plots are smallest with $E N D O W_{i}$ in Panels A and B. $S I Z E_{i}$ may therefore provide a better subgroup clustering. Moreover, Panel C shows the (non-)dispersed traders are large (small), while Panel D shows the (non-)electricity firms are small (large). And, among electricity firms, $68 \%$ are dispersed and $32 \%$ are non-dispersed traders, while among non-electricity firms, $43 \%$ are dispersed and $57 \%$ are non-dispersed traders.
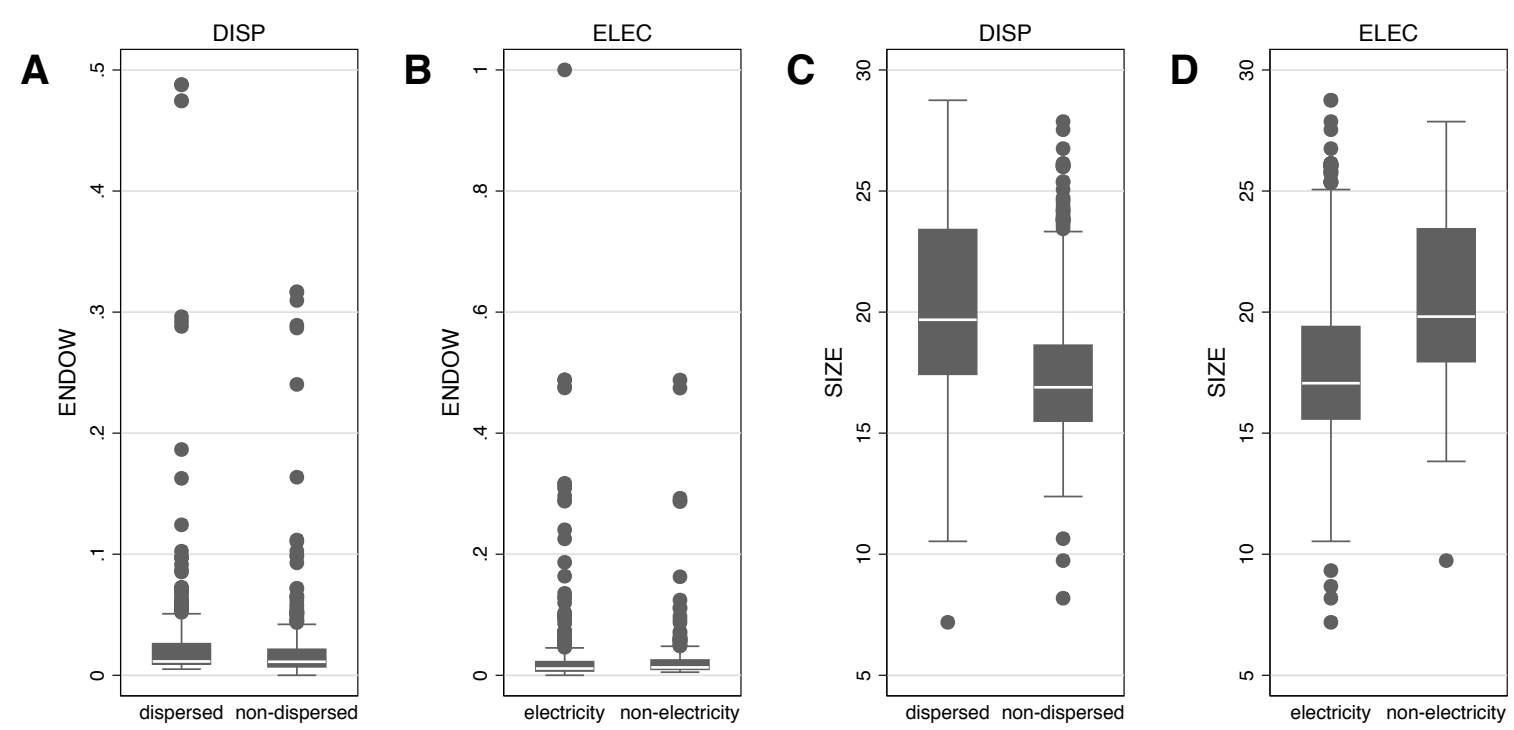

Figure A.1: Box-and-whisker plots on the distribution of energy firms over the subsets $\left(E L E C_{i}\right.$ and $\left.D I S P_{i}\right)$ and interaction terms $\left(E N D O W_{i}\right.$ and $\left.S I Z E_{i}\right)$. 
Table I: Overview and description of the variables

\begin{tabular}{|c|c|}
\hline \multicolumn{2}{|c|}{ Variable used in the empirical analysis } \\
\hline$T R A D E^{\star}$ & Daily net allowance trade (cf. Equation 2) \\
\hline$L C T^{\star} ; L C T^{2 \star}$ & Lagged compliance trajectory $L C T_{i, t}($ cf. Equation 4$) ;\left(L C T_{i, t}\right)^{2}$ \\
\hline$E D E M^{\bullet}$ & $\ln ($ monthly demand for national electricity (in MWh)) \\
\hline$\Delta F E D E M_{i, t}^{\bullet}$ & $\ln \left(\right.$ next month $\left.E D E M_{i, t}\right)-\ln \left(\right.$ current month $\left.E D E M_{i, t}\right)$ \\
\hline$\Delta L E D E M_{i, t}^{\bullet}$ & $\ln \left(\right.$ current month $\left.E D E M_{i, t}\right)-\ln \left(\right.$ previous month $\left.E D E M_{i, t}\right)$ \\
\hline$B R O W N^{\star}$ & Firm's (national) MWh production by fossil fuels (in \%) \\
\hline$C O A L^{\diamond}$ & Global Coal New Castle Price Index \\
\hline$G A S^{\diamond}$ & London Natural Gas Price Index \\
\hline$S P R E A D^{\star}$ & Coal-gas price returns: $\ln \left(C O A L_{t}-G A S_{t}\right)$ \\
\hline$B S P R E A D^{\star}$ & Weighted coal-gas price returns: $B R O W N_{i, t} * \ln \left(C O A L_{t}-G A S_{t}\right)$ \\
\hline$B D I N D E X^{\star}$ & Bi-directional index (cf. Equation 3) \\
\hline$B S S^{\diamond}$ & Buy-and-Sell Signal: $C O 2 S P O T_{t}-30$ day $C O 2 S P O T_{t}$ moving avg \\
\hline$C C A^{\diamond}$ & $\begin{array}{l}\text { Cost of Carry Arbitrage: } C O 2 F U T_{t}-C O 2 S P O T_{t} * e^{r T} \\
\text { where } r \text { equals the daily 1-month EURIBOR rate }\end{array}$ \\
\hline$C O 2 F U T^{\diamond}$ & ICE Phase I average continuous futures $\mathrm{CO}_{2}$ price \\
\hline$C O 2 S P O T^{\diamond}$ & EEX-EU $\mathrm{CO}_{2}$ settlement (spot) price \\
\hline$S A M E G U O^{\star}$ & $\begin{array}{l}\text { Daily average of dummy: } 1 \text { if trade partner belongs to same Global } \\
\text { Ultimate Owner (GUO), } 0 \text { otherwise (GUOs have } \geq 50,01 \% \text { of shares) }\end{array}$ \\
\hline$D I S P^{\circ}$ & $\begin{array}{l}1 \text { if } R T A_{i}>\text { sample quantile, } 0 \text { otherwise, where } \\
R T A_{i}=\left(\frac{1}{T} \sum_{t=1}^{T} P U R C H_{i t}+S E L L_{i t}\right) /\left(\sum_{t=1}^{T} P U R C H_{i t}+S E L L_{i t}\right)\end{array}$ \\
\hline$E L E C^{\circ}$ & 1 if controls at least one electricity installation, and 0 otherwise \\
\hline$E N D O W^{\circ}$ & 1 if $E N D O W_{i}$ (cf. Appendix A.3) > sample quantile, 0 otherwise \\
\hline$S I Z E^{\circ}$ & 1 if $\ln ($ total assets $2004-2009$ average $)>$ sample quantile, 0 otherwise \\
\hline
\end{tabular}

Variables underlying the $E N D O W_{i}$ composite indicator

\begin{tabular}{ll}
\hline$C A R B 05^{\circ}-$ & Firm's national $\mathrm{t}_{2}$ emissions / national electricity MWh production \\
$C A R B 07^{\circ}$ & over 2005, 2006, and 2007 \\
$D O M(F O R)^{\circ}$ & \# Domestic (foreign) intra-conglomerate installations \\
$(N) E C O N^{\circ}$ & \# Intra-conglomerate electricity firms (domestic and foreign) \\
$G S E C T O R^{\circ}$ & Gini-equality on spread of within-GUO industry categories (footnote 9) \\
$G F U E L 04(09)^{\circ}$ & Gini-equality on spread of within-GUO fuel categories in 2004 (2009) \\
& $\left(B R O W N_{i, t}+H Y D R O_{i, t}+N U C L E A R_{i, t}+R E N E W A B L E_{i, t}=1\right)$ \\
$M S H A R E^{\circ}$ & Average 2004, 2009 (\%)-market share national MWh electricity production \\
\hline
\end{tabular}

The variables are grouped according to the methodology subsections 3.3, 3.4, 3.5), and 3.6, and include the variables used for the composite indicator, $E N D O W_{i}$. The following symbols indicate the unit-frequency: $\circ=$ firm $/$ constant; $\star=$ firm/trading day; $\bullet=$ country $/$ monthly; $\diamond$ $=$ EU-wide/trading day. 
Table II: Statistics on determinants clustered by autarky and trade frequency: part I

\begin{tabular}{|c|c|c|c|c|c|c|c|c|c|}
\hline \multirow[b]{2}{*}{ Variable } & \multirow[b]{2}{*}{ Stat. } & \multicolumn{2}{|c|}{ Elec. prod. } & \multicolumn{2}{|c|}{ Non-elec. prod. } & \multicolumn{2}{|c|}{ Disp. traders } & \multicolumn{2}{|c|}{ Non-disp. traders } \\
\hline & & ENDOW & SIZE & ENDOW & SIZE & ENDOW & SIZE & ENDOW & SIZE \\
\hline \multirow[t]{2}{*}{ TRADE } & mean & -0.01 & -0.02 & -0.01 & -0.02 & -0.01 & -0.04 & -0.01 & -0.01 \\
\hline & $\mathrm{sd}$ & 1.64 & 0.67 & 0.95 & 0.63 & 1.63 & 0.92 & 0.47 & 0.46 \\
\hline \multirow[t]{2}{*}{ TRADE } & mean & 0.05 & 0.04 & -0.01 & 0.01 & 0.04 & 0.04 & -0.01 & -0.01 \\
\hline & sd & 1.97 & 2.06 & 1.04 & 1.35 & 1.96 & 2.05 & 0.46 & 0.48 \\
\hline \multirow[t]{2}{*}{$\mathrm{LCT}$} & mean & 1.81 & 1.69 & 3.64 & 2.99 & 1.96 & 1.19 & 4.21 & 3.48 \\
\hline & $\mathrm{sd}$ & 12.50 & 10.01 & 9.99 & 9.30 & 12.30 & 10.64 & 9.01 & 8.75 \\
\hline \multirow[t]{2}{*}{ LCT } & mean & 3.09 & 2.77 & 2.37 & 3.19 & 1.99 & 2.29 & 3.41 & 4.58 \\
\hline & $\mathrm{sd}$ & 12.24 & 13.01 & 10.33 & 11.28 & 12.47 & 13.01 & 9.19 & 9.73 \\
\hline \multirow[t]{2}{*}{$\mathrm{LCT}^{\wedge} 2$} & mean & 159.48 & 103.05 & 113.08 & 95.48 & 155.22 & 114.58 & 98.88 & 88.71 \\
\hline & sd & 65.02 & 45.67 & 55.86 & 40.85 & 61.57 & 43.36 & 49.17 & 38.46 \\
\hline \multirow[t]{2}{*}{$\mathrm{LCT}^{\wedge} 2$} & mean & 159.22 & 176.91 & 112.36 & 137.47 & 159.41 & 174.40 & 96.13 & 115.59 \\
\hline & $\mathrm{sd}$ & 77.56 & 69.93 & 55.52 & 64.18 & 69.17 & 65.14 & 49.86 & 62.67 \\
\hline \multirow{2}{*}{\multicolumn{2}{|c|}{$\begin{array}{r}\text { BSPREADmea } \\
\text { sd }\end{array}$}} & 2.51 & 2.61 & 0 & 0 & 1.06 & 0.41 & 0.41 & 0.45 \\
\hline & & 1.41 & 1.42 & 0 & 0 & 1.55 & 1.12 & 1.08 & 1.15 \\
\hline \multirow{2}{*}{\multicolumn{2}{|c|}{$\begin{array}{c}\text { BSPREADmean } \\
\text { sd }\end{array}$}} & 2.63 & 2.56 & 0 & 0 & 1.21 & 1.42 & 0.76 & 0.81 \\
\hline & & 1.340 & 1.36 & 0 & 0 & 1.57 & 1.62 & 1.42 & 1.43 \\
\hline \multirow[t]{2}{*}{ SPREAD } & mean & 3.78 & 3.78 & J & 3.78 & 3.78 & 3.78 & 3.78 & 3.78 \\
\hline & sd & 0.27 & 0.27 & 0.21 & 0.27 & 0.27 & 0.27 & 0.27 & 0.27 \\
\hline \multirow[t]{2}{*}{ SPREAD } & mean & 3.78 & 3.78 & 3.78 & 3.78 & 3.78 & 3.78 & 3.78 & 3.78 \\
\hline & $\mathrm{sd}$ & 0.27 & 0.27 & 0.27 & 0.27 & 0.27 & 0.27 & 0.27 & 0.27 \\
\hline \multirow[t]{2}{*}{$\triangle \mathrm{LEDEM}$} & mean & -0.01 & -0.01 & -0.004 & -0.01 & -0.01 & -0.01 & -0.003 & -0.004 \\
\hline & sd & 0.11 & 0.12 & 0.10 & 0.10 & 0.11 & 0.13 & 0.09 & 0.09 \\
\hline \multirow[t]{2}{*}{$\triangle \mathrm{LEDEM}$} & mean & -0.01 & -0.01 & -0.01 & -0.004 & -0.01 & -0.01 & -0.004 & -0.004 \\
\hline & $\mathrm{sd}$ & 0.11 & 0.11 & 0.11 & 0.10 & 0.12 & 0.11 & 0.09 & 0.10 \\
\hline \multirow[t]{2}{*}{ EDEM } & mean & 9.71 & 9.66 & 9.32 & 9.37 & 9.63 & 9.50 & 9.25 & 9.38 \\
\hline & sd & 1.27 & 1.33 & 1.17 & 1.16 & 1.28 & 1.37 & 1.12 & 1.11 \\
\hline \multirow[t]{2}{*}{ EDEM } & mean & 9.93 & 9.89 & 9.62 & 9.58 & 9.80 & 9.80 & 9.67 & 9.57 \\
\hline & $\mathrm{sd}$ & 1.24 & 1.23 & 1.17 & 1.20 & 1.26 & 1.22 & 1.14 & 1.22 \\
\hline \multirow[t]{2}{*}{$\Delta$ FEDEM } & mean & 0.01 & 0.01 & 0.01 & 0.01 & 0.01 & 0.01 & 0.004 & 0.01 \\
\hline & $\mathrm{sd}$ & 0.10 & 0.10 & 0.09 & 0.09 & 0.09 & 0.10 & 0.09 & 0.08 \\
\hline \multirow[t]{2}{*}{$\Delta$ FEDEM } & mean & 0.01 & 0.01 & 0.01 & 0.01 & 0.01 & 0.01 & 0.01 & 0.004 \\
\hline & $\mathrm{sd}$ & 0.09 & 0.09 & 0.09 & 0.09 & 0.10 & 0.092 & 0.08 & 0.09 \\
\hline
\end{tabular}

The two upper (lower) rows of the variables contain the means and standard deviations (sd) of the less (more) endowed or small (large) firms. 
Table III: Statistics on determinants clustered by autarky and trade frequency: part II

\begin{tabular}{|c|c|c|c|c|c|c|c|c|c|}
\hline \multirow[b]{2}{*}{ Variable } & \multirow[b]{2}{*}{ Stat. } & \multicolumn{2}{|c|}{ Elec. prod. } & \multicolumn{2}{|c|}{ Non elec. prod. } & \multicolumn{2}{|c|}{ Disp. traders } & \multicolumn{2}{|c|}{ Non-disp. traders } \\
\hline & & ENDOW & SIZE & ENDOW & SIZE & ENDOW & SIZE & ENDOW & SIZE \\
\hline \multirow[t]{2}{*}{ BDINDEX } & mean & 0.01 & -0.002 & 0.002 & -0.002 & 0.01 & -0.004 & 0.002 & -0.001 \\
\hline & $\mathrm{sd}$ & 0.25 & 0.07 & 0.15 & 0.07 & 0.25 & 0.10 & 0.10 & 0.05 \\
\hline \multirow[t]{2}{*}{ BDINDEX } & mean & 0.02 & 0.02 & -0.001 & 0.01 & 0.01 & 0.02 & 0.002 & 0.01 \\
\hline & $\mathrm{sd}$ & 0.31 & 0.32 & 0.15 & 0.22 & 0.29 & 0.31 & 0.11 & 0.17 \\
\hline \multirow[t]{2}{*}{ BSS } & mean & -0.16 & -0.16 & -0.16 & -0.16 & -0.16 & -0.16 & -0.16 & -0.16 \\
\hline & sd & 0.34 & 0.34 & 0.34 & 0.34 & 0.34 & 0.34 & 0.34 & 0.34 \\
\hline \multirow[t]{2}{*}{ BSS } & mean & -0.16 & -0.16 & -0.16 & -0.16 & -0.16 & -0.16 & -0.16 & -0.16 \\
\hline & $\mathrm{sd}$ & 0.34 & 0.34 & 0.34 & 0.34 & 0.34 & 0.34 & 0.34 & 0.34 \\
\hline \multirow[t]{2}{*}{$\mathrm{CCA}$} & mean & 0.40 & 0.40 & 0.40 & 0.40 & 0.40 & 0.40 & 0.40 & 0.40 \\
\hline & $\mathrm{sd}$ & 0.53 & 0.53 & 0.53 & 0.53 & 0.53 & 0.53 & 0.53 & 0.53 \\
\hline \multirow[t]{2}{*}{$\mathrm{CCA}$} & mean & 0.40 & 0.40 & 0.40 & 0.40 & 0.40 & 0.40 & 0.40 & 0.40 \\
\hline & $\mathrm{sd}$ & 0.53 & 0.53 & 0.53 & 0.53 & 0.53 & 0.53 & 0.53 & 0.53 \\
\hline \multirow{4}{*}{$\begin{array}{l}\text { SAMEGUC } \\
\text { SAMEGUC }\end{array}$} & mean & 0.09 & 0.03 & 0.03 & 0.03 & 0.07 & 0.03 & 0.02 & 0.02 \\
\hline & $\mathrm{sd}$ & 0.24 & 0.16 & 0.16 & 0.15 & 0.21 & 0.16 & 0.15 & 0.13 \\
\hline & mean & 0.08 & 0.08 & 0.04 & 0.04 & 0.07 & 0.07 & 0.01 & 0.02 \\
\hline & $\mathrm{sd}$ & 0.21 & 0.23 & 0.18 & 0.18 & 0.21 & 0.21 & 0.11 & 0.13 \\
\hline
\end{tabular}

The two upper (lower) rows of the variables contain the means and standard deviations (sd) of the less (more) endowed or small (large) firms. 
Table IV: Panel data regressions on $T R A D E_{i, t}$

\begin{tabular}{|c|c|c|c|c|c|c|c|c|}
\hline \multirow[b]{2}{*}{ Variable } & \multicolumn{4}{|c|}{ ENDOW } & \multicolumn{4}{|c|}{ SIZE } \\
\hline & $\operatorname{Disp}^{\circ} N$ & Non-disp $^{\bullet}$ & Elec $^{\bullet} \mathrm{N}$ & Non-elec $^{\circ}$ & $\operatorname{Disp}^{\circ} \mathrm{N}$ & Non-disp ${ }^{\bullet}$ & Elec $^{\bullet} \mathrm{I}$ & Non-elec $^{\circ}$ \\
\hline 1a) ENDOW & 0.000 & $-0.399^{*}$ & $1.564^{*}$ & * $\quad 0.000$ & & & & \\
\hline 2a) SIZE & & & & & -0.186 & $-1.832^{*}$ & $0.791^{*}$ & $*-0.226^{*}$ \\
\hline 3a) $\mathrm{LCT}$ & 0.000 & $-0.001^{*}$ & -0.001 & -0.001 & 0.000 & 0.000 & -0.001 & -0.001 \\
\hline 4a) $\mathrm{LCT}^{\wedge} 2$ & 0.000 & $0.000^{*}$ & $-0.001^{*}$ & * $0.000^{*}$ & $0.000^{*}$ & $0.000^{*}$ & $-0.001^{*}$ & * $0.001^{*}$ \\
\hline 5a) BSPREAD & 0.014 & 0.000 & $-0.015^{*}$ & * $\quad 0.000$ & $0.041^{*}$ & 0.001 & $-0.008^{*}$ & $* \quad 0.000$ \\
\hline 6a) SPREAD & 0.021 & $0.020^{*}$ & $0.077^{*}$ & $*-0.018$ & 0.009 & $0.021^{*}$ & $0.097^{*}$ & $*-0.028$ \\
\hline 7a) $\triangle$ LEDEM & 0.030 & 0.008 & -0.003 & -0.004 & -0.037 & 0.025 & -0.073 & 0.017 \\
\hline 8a) EDEM & $0.074^{*}$ & $* \quad 0.002$ & $0.023^{*}$ & * $\quad 0.015$ & $0.078^{*}$ & 0.000 & $0.026^{*}$ & $* \quad 0.027$ \\
\hline 9a) $\triangle$ FEDEM & 0.020 & -0.003 & 0.025 & 0.021 & -0.066 & 0.016 & -0.110 & 0.043 \\
\hline 10a) BDINDEX & $3.447^{*}$ & * $1.685^{*}$ & $2.946^{*}$ & * $4.226^{*}$ & ${ }^{k} \quad 3.336^{*}$ & $0.770^{*}$ & $3.066^{*}$ & * $3.086^{*}$ \\
\hline 11a) BSS & 0.000 & 0.000 & -0.005 & -0.002 & -0.001 & $-0.012^{*}$ & 0.007 & -0.016 \\
\hline 12a) $\mathrm{CCA}$ & 0.013 & 0.000 & -0.009 & $0.024^{*}$ & ${ }^{k}-0.004$ & 0.003 & $-0.024^{*}$ & $* \quad 0.019 *$ \\
\hline 13a) SAMEGUO & $-0.678^{*}$ & $* \quad 3.567^{*}$ & $-1.390^{*}$ & * $0.767^{*}$ & ${ }^{k}-0.595^{*}$ & $2.347^{*}$ & $-0.925^{*}$ & $*-0.066$ \\
\hline 14a) QUARTER1 & $-0.059^{*}$ & $*-0.004$ & $-0.068^{*}$ & $*-0.007$ & $-0.069^{*}$ & * -0.001 & $-0.077^{*}$ & $*-0.011$ \\
\hline 15a) QUARTER2 & -0.015 & 0.002 & -0.023 & -0.004 & -0.018 & -0.005 & -0.008 & $-0.018^{*}$ \\
\hline 16a) QUARTER4 & $-0.030^{*}$ & $* \quad 0.001$ & -0.025 & -0.005 & $-0.031^{*}$ & 0.005 & -0.013 & $-0.023^{*}$ \\
\hline CONSTANT & -0.412 & $-3.241^{*}$ & $-0.568^{*}$ & $*-0.885^{*}$ & 0.000 & $-0.578^{*}$ & $-0.351^{*}$ & $* \quad 0.000$ \\
\hline 3b) $\mathrm{LCT}$ & -0.001 & $0.000^{*}$ & 0.000 & 0.000 & 0.000 & 0.000 & 0.001 & 0.001 \\
\hline 4b) $\mathrm{LCT}^{\wedge} 2$ & $0.001^{*}$ & 0.000 & $0.000^{*}$ & 0.000 & $0.000^{*}$ & $0.000^{*}$ & $0.001^{*}$ & $*-0.001^{*}$ \\
\hline 5b) BSPREAD & 0.044 & 0.001 & $0.021^{*}$ & * $\quad 0.000$ & $-0.039^{*}$ & * -0.002 & $0.008^{*}$ & $* \quad 0.000$ \\
\hline 6b) SPREAD & -0.033 & -0.006 & -0.019 & 0.002 & -0.014 & $-0.021^{*}$ & $-0.096^{*}$ & $* \quad 0.025$ \\
\hline 7b) $\triangle \mathrm{LEDEM}$ & -0.111 & -0.036 & -0.110 & -0.011 & 0.038 & -0.034 & 0.078 & -0.024 \\
\hline 8b) EDEM & -0.051 & -0.002 & -0.005 & -0.011 & $-0.075^{*}$ & 0.000 & $-0.026^{*}$ & $*-0.027$ \\
\hline 9b) $\triangle$ FEDEM & $-0.138^{*}$ & $*-0.009$ & $-0.196^{*}$ & $*-0.027$ & 0.055 & -0.028 & $0.116^{*}$ & $*-0.057$ \\
\hline 10b) BDINDEX & $0.288^{*}$ & * $0.313^{*}$ & $0.562^{*}$ & $*-0.795^{*}$ & $5.815^{*}$ & $7.603^{*}$ & $6.127^{*}$ & $* 5.706^{*}$ \\
\hline 11b) BSS & -0.008 & $-0.010^{*}$ & 0.013 & -0.013 & 0.005 & $0.013^{*}$ & -0.006 & 0.017 \\
\hline 12b) $\mathrm{CCA}$ & $-0.036^{*}$ & $*-0.001$ & -0.022 & $-0.026^{*}$ & 0.005 & -0.004 & $0.024^{*}$ & $*-0.019 *$ \\
\hline 13b) SAMEGUO & $1.056^{*}$ & $*-0.357^{*}$ & $1.698^{*}$ & * $\quad 0.080$ & $0.895^{*}$ & * $-1.769 *$ & $1.274^{*}$ & $* 0.471^{*}$ \\
\hline 14b) QUARTER1 & 0.019 & 0.001 & 0.019 & 0.002 & $0.068^{*}$ & 0.001 & $0.075^{*}$ & $* \quad 0.011$ \\
\hline 15b) QUARTER2 & 0.003 & -0.003 & 0.036 & -0.012 & 0.017 & 0.007 & 0.008 & $0.020 *$ \\
\hline 16b) QUARTER4 & 0.011 & 0.005 & 0.023 & -0.004 & 0.027 & -0.003 & 0.007 & $0.025^{*}$ \\
\hline$R^{2}$ (within) & 0.210 & 0.347 & 0.248 & 0.336 & 0.303 & 0.648 & 0.257 & 0.412 \\
\hline $\mathrm{N}$ & 353050 & 333402 & 229636 & 456816 & 353050 & 333402 & 229636 & 456816 \\
\hline No. groups & 575 & 543 & 374 & 744 & 575 & 543 & 374 & 744 \\
\hline
\end{tabular}

Methodologies used are fixed effects (within) regressions with Driscoll-Kraay standard errors (symbol: o), and panel-corrected Prais-Winsten standard errors (symbol: •). Values are coefficients, and marked with $*$ if significant at $95 \%$. The variables appended with b) are $S I Z E_{i}$ or $E N D O W_{i}$ interactions terms. 
Table V: The p-values from the joint significance (Wald) tests on Table IV variables

\begin{tabular}{|c|c|c|c|c|c|c|c|c|}
\hline \multirow[b]{2}{*}{ Variable } & \multicolumn{4}{|c|}{ ENDOW } & \multicolumn{4}{|c|}{ SIZE } \\
\hline & \multicolumn{4}{|c|}{ Disp. Non-disp. Ele } & \multicolumn{2}{|c|}{ Disp. Non-disp. } & \multicolumn{2}{|c|}{ Elec. Non-elec } \\
\hline \multicolumn{9}{|c|}{ Wald tests: base and interaction terms of $E N D O W_{i}$ or $\left.S I Z E_{i}\right)$} \\
\hline Full model (i.e. F-test) & 0.00 & 0.00 & 0.00 & 0.00 & 0.00 & 0.00 & 0.00 & 0.00 \\
\hline $\mathrm{LCT}, \mathrm{LCT}^{\wedge} 2$ & 0.01 & 0.00 & 0.00 & 0.00 & 0.001 & 0.00 & 0.00 & 0.00 \\
\hline BSPREAD, SPREAD & 0.00 & 0.001 & 0.00 & 0.11 & 0.05 & 0.02 & 0.00 & 0.12 \\
\hline EDEM, LAG- \& FUT- & 0.01 & 0.42 & 0.00 & 0.90 & 0.04 & 0.33 & 0.00 & 0.14 \\
\hline BDINDEX & 0.00 & 0.00 & 0.00 & 0.00 & 0.00 & 0.00 & 0.00 & 0.00 \\
\hline BSS & 0.75 & 0.03 & 0.79 & 0.02 & 0.20 & 0.08 & 0.80 & 0.04 \\
\hline $\mathrm{CCA}$ & 0.02 & 0.91 & 0.02 & 0.004 & 0.53 & 0.45 & 0.09 & 0.07 \\
\hline SAMEGUO & 0.00 & 0.00 & 0.00 & 0.00 & 0.00 & 0.00 & 0.00 & 0.00 \\
\hline QUARTER dummies & 0.01 & 0.26 & 0.00 & 0.02 & 0.001 & 0.09 & 0.00 & 0.01 \\
\hline \multicolumn{9}{|c|}{ Wald tests: only interaction terms of $E N D O W_{i}$ or $\left.S I Z E_{i}\right)$} \\
\hline Full model & 0.00 & 0.00 & 0.00 & 0.00 & 0.00 & 0.00 & 0.00 & 0.00 \\
\hline $\mathrm{LCT}, \mathrm{LCT}^{\wedge} 2$ & 0.02 & 0.00 & 0.00 & 0.62 & 0.15 & 0.00 & 0.00 & 0.00 \\
\hline BSPREAD, SPREAD & 0.12 & 0.00 & 0.00 & 0.87 & 0.14 & 0.00 & 0.00 & 0.03 \\
\hline EDEM, LAG- \& FUT- & 0.06 & 0.00 & 0.00 & 0.89 & 0.02 & 0.00 & 0.00 & 0.04 \\
\hline BDINDEX & 0.00 & 0.00 & 0.00 & 0.00 & 0.00 & 0.00 & 0.00 & 0.00 \\
\hline BSS & 0.57 & 0.00 & 0.00 & 0.07 & 0.36 & 0.00 & 0.00 & 0.02 \\
\hline $\mathrm{CCA}$ & 0.02 & 0.00 & 0.00 & 0.001 & 0.28 & 0.00 & 0.00 & 0.02 \\
\hline SAMEGUO & 0.00 & 0.00 & 0.00 & 0.71 & 0.00 & 0.00 & 0.00 & 0.00 \\
\hline QUARTER dummies & 0.49 & 0.00 & 0.00 & 0.27 & 0.001 & 0.00 & 0.00 & 0.02 \\
\hline
\end{tabular}


Table A.I: Autarky index: ENDOW

\begin{tabular}{|c|c|c|c|c|c|c|c|c|}
\hline \multirow[b]{2}{*}{$\mathbf{A}$} & \multicolumn{4}{|c|}{ Electricity firms } & \multicolumn{3}{|c|}{ Non-electricity firms } & \multirow[b]{2}{*}{ Cum. } \\
\hline & EV. & Diff. & Prop. & Cum. & $\mathrm{EV}$ & Diff. & Prop. & \\
\hline Factor 1 & 3.50 & 0.53 & 0.47 & 0.47 & 2.20 & 1.86 & 1 & 1 \\
\hline Factor2 & 2.97 & 1.98 & 0.40 & 0.87 & 0.34 & 0.25 & 0.15 & 1.15 \\
\hline Factor3 & 0.996 & 0.74 & 0.13 & 1 & 0.09 & 0.24 & 0.04 & 1.20 \\
\hline Factor 4 & 0.25 & 0.10 & 0.03 & 1.03 & -0.15 & 0.13 & -0.07 & 1.13 \\
\hline Factor5 & 0.16 & 0.16 & 0.02 & 1.06 & -0.28 & n.a. & -0.13 & 1 \\
\hline Factor6 & 0.00 & 0.00 & 0 & 1.06 & & & & \\
\hline Factor 7 & 0.00 & 0.02 & 0 & 1.06 & & & & \\
\hline Factor 8 & -0.02 & 0.04 & 0.00 & 1.05 & & & & \\
\hline Factor 9 & -0.07 & 0.04 & -0.01 & 1.04 & & & & \\
\hline Factor 10 & -0.10 & 0.12 & -0.01 & 1.03 & & & & \\
\hline Factor 11 & -0.22 & n.a. & -0.0299 & 1 & & & & \\
\hline B & $\mathrm{F} 1$ & $\mathrm{~F} 2$ & F3 & Uniq. & $\mathrm{F} 1$ & Uniq. & & \\
\hline DOM & 0.38 & 0.10 & -0.04 & 0.84 & 0.22 & 0.95 & & \\
\hline FOR & 0.75 & 0.19 & 0.24 & 0.35 & 0.84 & 0.29 & & \\
\hline $\mathrm{ECON}$ & 0.86 & 0.21 & 0.23 & 0.16 & 0.89 & 0.20 & & \\
\hline NECON & 0.75 & 0.23 & 0.51 & 0.12 & 0.72 & 0.48 & & \\
\hline GSECTOR & $\mathrm{R}-0.22$ & -0.11 & -0.24 & 0.88 & -0.35 & 0.88 & & \\
\hline GFUEL04 & -0.75 & -0.14 & 0.58 & 0.07 & & & & \\
\hline GFUEL09 & -0.71 & -0.13 & 0.43 & 0.29 & & & & \\
\hline MSHARE & 0.38 & 0.07 & -0.19 & 0.81 & & & & \\
\hline CARB05 & -0.27 & 0.96 & -0.03 & 0.001 & & & & \\
\hline CARB06 & -0.27 & 0.96 & -0.03 & 0.00 & & & & \\
\hline CARB07 & -0.27 & 0.96 & -0.03 & 0.001 & & & & \\
\hline
\end{tabular}

Panel A contains the iterated principal factors (unrotated), and panel $\mathrm{B}$ the factor loadings and unique variances. The columns contain the eigenvalues ("EV"), the eigenvalue difference ("Diff."), the variance proportion ("Prop."), cumulative variance proportion ("Cum."), uniqueness ("Uniq."), and factors 1 to 3 (F1-F3). 


\section{Authors contacts:}

Thijs Jong (corresponding author)

University of Groningen

Department of Law and Economics

the Netherlands

Email: m.a.p.jong@rug.nl

\section{Alexander C.M. Zeitlberger}

Department of Finance

Karl-Franzens University of Graz

Austria

Email: alexander.zeitlberger@uni-graz.at 